TITLE:

\title{
Effect of twinning and detwinning on inelastic behavior during unloading in a magnesium alloy sheet
}

\section{$\operatorname{AUTHOR}(\mathrm{S})$ :}

Hama, Takayuki; Kitamura, Naoya; Takuda, Hirohiko

\section{CITATION:}

Hama, Takayuki ... [et al]. Effect of twinning and detwinning on inelastic behavior during unloading in a magnesium alloy sheet. Materials Science and Engineering: A 2013, 583: 232-241

\section{ISSUE DATE:}

2013-10

URL:

http://hdl.handle.net/2433/178736

\section{RIGHT:}

(C) 2013 Elsevier B.V.; This is not the published version. Please cite only the published version.; この論文は出版社版でありません。引用の際に は出版社版をご確認ご利用ください。 
Effect of Twinning and Detwinning on Inelastic Behavior during Unloading in a Magnesium Alloy Sheet

Takayuki HAMA ${ }^{* 1, * 2}$

Naoya KITAMURA $^{* 1}$

Hirohiko TAKUDA $^{* 1}$

*1 Graduate School of Energy Science, Kyoto University, Yoshida-honmachi, Sakyo-ku, Kyoto 606-8501, Japan

*2 Advanced Manufacturing Metrology Laboratory, RIKEN, 2-1 Hirosawa, Wako-shi, Saitama 351-0198, Japan

Corresponding author: Takayuki HAMA

Graduate School of Energy Science, Kyoto University

Yoshida-Honmachi, Sakyo-ku, Kyoto 606-8501, Japan

TEL: $\quad+81-(0) 75-753-5418$

FAX: $\quad+81-(0) 75-753-5428$

E-mail: hama@energy.kyoto-u.ac.jp 


\section{ABSTRACT}

We investigate the nonlinear response arising during unloading under in-plane uniaxial compression of a rolled magnesium alloy sheet using a crystal plasticity finite-element method, focusing on the effects of twinning and detwinning, and discuss the mechanism that causes the nonlinear response to be more pronounced under uniaxial compression than under uniaxial tension. In the simulation, we employed a twinning and detwinning model recently proposed by the authors. From numerical experiments, we confirmed that, as already noted in previous studies, detwinning activity plays an important role in the nonlinear response during unloading. However, we also found that the basal slip could become very active during unloading because of the dispersion of crystallographic orientations caused by twinning activity during loading, which is another factor in the pronounced nonlinear response during unloading under uniaxial compression. We conclude that the nonlinear response during unloading is more pronounced under uniaxial compression than under uniaxial tension because of these 2 factors-i.e., the detwinning activity and the pronounced basal slip activity—which are not present under uniaxial tension.

Keywords:

Magnesium alloy sheet

Crystal plasticity

Finite element method

Unloading 
Twinning

Detwinning

Texture

\section{Introduction}

Lightweight materials are increasingly in demand to reduce the environmental impact of transport equipment [1, 2]. Magnesium (Mg) alloys, the lightest metals used for structural components, recently have received much attention and the formability of $\mathrm{Mg}$ alloy sheets has been studied extensively [3-10].

It is well established that most rolled $\mathrm{Mg}$ alloy sheets show characteristic deformation behaviors, including an asymmetric deformation behavior between tension and compression [11, 12] and an anisotropic work-hardening behavior [13, 14], because of the hexagonal close-packed (hcp) structure. A strong nonlinear response during unloading is also a well-known characteristic behavior. Cáceres et al. [15] and Mann et al. [16] first examined this behavior in detail experimentally and concluded that the observed nonlinear response could be understood in terms of the partial reversal of $\left\{\begin{array}{llll}1 & 0 & \overline{1} & 2\end{array}\right\}$ twinning, i.e., detwinning, during unloading. Thereafter, other researchers studied this behavior, with similar conclusions $[17,18]$. A detailed survey of the literature on this behavior can be found in Hama and Takuda [19].

Previously, we experimentally examined the nonlinear response during unloading under various loading paths, such as under tension, compression, and compression followed by tension (compression-tension) [19]. We found that the nonlinear response was much more pronounced when the twinning and the detwinning were active, i.e., under compression and compression-tension, respectively, than it was when they were not active, i.e., under tension. 
Similar results were reported in Muránsky et al. [18]. Clearly, the mechanism causing the nonlinear response during unloading would be different under tension and compression. The difference in the detwinning activity during unloading may be responsible for the difference in the nonlinear response between tension and compression as explained in the previous study [19], but the detailed mechanism of the nonlinear response is still unclear. For instance, twinning activity involves a significant change in texture during deformation. Such a significant change in the texture also would affect the nonlinear deformation during unloading because the initial texture of the material affects the deformation during unloading [19, 20]. However, the effect of the texture change during loading on the nonlinear deformation during unloading has not been investigated.

Crystal plasticity models are powerful tools that can be used to understand the interaction between mesoscopic crystalline and macroscopic deformation in metals. An increasing number of studies have actively employed the models to analyze the deformation of $\mathrm{Mg}$ alloys [14, 19, 21-43]. The present authors simulated the deformation during unloading of a rolled $\mathrm{Mg}$ alloy sheet using a crystal plasticity finite-element method [19]. The nonlinear response under in-plane uniaxial tension was predicted well in the simulation and the simulation result indicated that this nonlinear deformation is attributable to the activity of the basal slip during unloading. It should be noted that detwinning was neglected in the simulation because no well-established detwinning model existed at the time of the simulation. However, detwinning should be taken into account when the unloading process under in-plane uniaxial compression is simulated with a significant amount of twinning activity. Recently, Wang et al. [20] proposed a detwinning model and simulated the deformation of extruded Mg alloys during cyclic loading-unloading. They reported that detwinning activity was the most important factor in nonlinear deformation during unloading 
when twinning was activated during loading. However, the effect of the texture change during loading on the nonlinear deformation during unloading was not investigated in their study.

Recently, the present authors also proposed a simple detwinning model and showed that the stress-strain curves under various loading paths, including compression-tension and tension-compression-tension, could be predicted well [36]. Such progress in the simulation technique permits a study that numerically examines the effect of twinning and detwinning on the nonlinear response during unloading.

In the present study, a simulation of the loading-unloading process in a rolled $\mathrm{Mg}$ alloy sheet under uniaxial compression was performed using a crystal plasticity finite-element method that considers detwinning, and the effect of twinning and detwinning on the deformation during unloading was examined. We also discuss the mechanism that causes the nonlinear response to be more pronounced under uniaxial compression than under uniaxial tension.

\section{Crystal Plasticity Finite-Element Method}

\subsection{Basic Formulation}

The crystal plasticity finite-element method used in the present study follows that used in our previous studies $[14,19]$. The new detwinning model [36] is also employed. In the following, the formulations for the crystal plasticity model are explained briefly. The reader is referred to the literature $[14,19,36]$ for detailed information.

A static finite-element method based on an updated Lagrangian rate formulation is used [44, 45]. The rate-dependent crystal plasticity model [46, 47] explained below is incorporated into each Gauss point in finite elements. The rate tangent modulus method [46] is used for explicit time integration. The so-called $r_{m i n}$-strategy [48] is employed and the size of an increment is 
limited to prevent an excessive increase of the nonequilibrium between external and internal forces.

The crystalline slip is assumed to follow Schmid's law. The slip rate $\dot{\gamma}^{(\alpha)}$ of the $\alpha$-slip system is assumed given by the viscoplastic power law as follows

$$
\frac{\dot{\gamma}^{(\alpha)}}{\dot{\gamma}_{0}}=\left|\frac{\tau^{(\alpha)}}{\tau_{\mathrm{Y}}^{(\alpha)}}\right|^{\frac{1}{m}} \operatorname{sign}\left(\tau^{(\alpha)}-\tau_{\mathrm{kin}}^{(\alpha)}\right), \quad \tau^{(\alpha)}=\boldsymbol{s}^{(\alpha)} \cdot \boldsymbol{\sigma} \cdot \boldsymbol{m}^{(a)}, \quad \dot{\tau}_{\mathrm{Y}}^{(a)}=\sum_{\beta} q_{\alpha \beta} h\left|\dot{\gamma}^{(\beta)}\right|,
$$

where $\tau^{(\alpha)}$ is Schmid's resolved shear stress, $\tau_{\mathrm{Y}}^{(\alpha)}$ is the current slip resistance of the $\alpha$-slip system with $\tau_{\mathrm{Y}}^{(\alpha)}=\tau_{0}$ initially, $\dot{\gamma}_{0}$ is the reference strain rate, $m$ is the rate-sensitivity exponent, and $q_{\alpha \beta}$ with $\alpha=\beta$ and with $\alpha \neq \beta$ are the self- and latent-hardening moduli, respectively. The unit vectors $\boldsymbol{s}^{(\alpha)}$ and $\boldsymbol{m}^{(\alpha)}$ are the slip direction and the slip plane normal, respectively. $h$ is the rate of hardening; the hardening laws will be explained later.

It is established that kinematic hardening plays an important role when metals are subjected to reverse loading [49-51]. On the other hand, it was also reported that the effect of kinematic hardening on the deformation of a $\mathrm{Mg}$ alloy sheet during unloading under in-plane tension was negligible [19]. Therefore, to simplify the simulation model, the kinematic hardening is not taken into account in the present study.

\subsection{Slip Systems}

Following previous studies $[14,19,23,36]$, families of basal <a> slip systems, prismatic $<a>$ slip systems, and pyramidal $-2<a+c>$ slip systems, and 1 family of $\left\{\begin{array}{llll}1 & 0 & \overline{1} & 2\end{array}\right\}$ tension twinning systems, are used to model the mechanical behavior of a $\mathrm{Mg}$ alloy sheet. There are 3 basal, 3 prismatic, 6 pyramidal-2, and 6 tension-twinning systems. The slip/twinning plane 
normal and slip direction vectors for the employed systems are shown in Table 1. A treatment of twinning systems will be explained in the next section.

Two evolution laws are used for the rate of hardening, $h$ [Eq. (1)], in the forms

$$
h=h_{0}
$$

and

$$
h=h_{0}\left(1-\frac{\tau_{0}}{\tau_{\infty}}\right) \exp \left(-\frac{h_{0} \bar{\gamma}}{\tau_{\infty}}\right),
$$

where $\bar{\gamma}$ is the cumulative shear strain on all the slip systems and is given by

$$
\bar{\gamma}=\sum_{\alpha} \int\left|\dot{\gamma}^{(\alpha)}\right| \mathrm{d} t
$$

Linear hardening [Eq. (2)] is assumed for the basal slip and Voce hardening [Eq. (3)] is assumed for the prismatic slip and the pyramidal-2 slip.

\subsection{Twinning Systems}

In the framework of crystal plasticity analysis, several twinning models have been proposed [52-58], whereas the number of detwinning models is much smaller [27, 59]. In the present study, we employ a twinning model originally proposed by Van Houtte [52] and a detwinning model recently proposed by the authors [36]. The detwinning model was developed by extending the twinning model to detwinning. In the present models, the twinning systems are assumed to represent the twin boundary and the activity of the $\alpha$-twinning system is assumed to be described in terms of the resolved shear stress, $\tau^{(\alpha)}$, on the twin boundary, i.e., the plane of the $\alpha$ twinning system. The idea is described briefly as follows. 
In the twinning model, twinning is assumed to have a polar character, in which each system can be activated only by tension of the $c$-axis $\left(\tau^{(\alpha)}>0\right)$. Because the shear strain that arises in a grain due to twinning is mesoscopically similar to the shear induced by an activated slip system, the shear strain rate induced by twinning is calculated using Eq. (1), as is the case for slip deformation. The linear hardening [Eq. (2)] is assumed for the rate of hardening, $h$.

A statistical approach is used to model the lattice rotation due to twinning. Using the cumulative shear strain induced by twinning, $\bar{\gamma}_{\text {twin }}^{(\alpha)}$, the volume fraction of the $\alpha$-twinning system in a grain, $f^{(\alpha)}$, is calculated by $f^{(\alpha)}=\bar{\gamma}_{\text {twin }}^{(\alpha)} / \gamma_{\text {ref }}$, with $\gamma_{\text {ref }}$ being the shear strain when the grain is twinned entirely. This approximation holds if we assume that the shear in the grain is uniform $[52,60]$. Meanwhile a pseudo-random threshold value of volume fraction $f_{\text {th }}^{(\alpha)}$ is initially determined between 0.3 and 1.0 for each twinning system $[19,21,26]$. The volume fraction of the $\alpha$ twinning system, $f^{(\alpha)}$, is compared with $f_{\text {th }}^{(\alpha)}$ at each time increment, and when $f^{(\alpha)} \geq f_{\mathrm{th}}^{(\alpha)}$ is satisfied, all of the slip systems are rotated to a specific twinning orientation. The lattice rotation tensor due to twinning, $\boldsymbol{R}^{\mathrm{tw}}$, is given in the following form:

$$
\boldsymbol{R}^{t w}=2 \boldsymbol{m}^{(\alpha)} \otimes \boldsymbol{m}^{(\alpha)}-\boldsymbol{I}
$$

where $\boldsymbol{I}$ is the unit tensor and $\boldsymbol{m}^{(\alpha)}$ is the plane normal vector for the $\alpha$ twinning system. It should be noted that the twinning systems are not subjected to the lattice rotation because the twinning systems represent the twin boundary that corresponds to the twin planes of the matrix, as explained above. The shear strain due to twinning cannot arise in the grain after the lattice rotation due to twinning arises. 
When the shear strain due to twinning once arises in the $\alpha$ twinning system under $\tau^{(\alpha)}>0$, detwinning can be activated thereafter when $\tau^{(\alpha)}$ becomes negative. It is assumed that the shear strain rate and the rate of hardening for detwinning are also given by Eqs. (1) and (2). Denoting the cumulative shear strain that arises on the $\alpha$ twinning system during twinning as $\bar{\gamma}_{\text {twin }}^{(\alpha) \max }$, detwinning can be activated on the $\alpha$ twinning system until the cumulative shear strain due to detwinning, $\bar{\gamma}_{\text {ut }}$, reaches $\bar{\gamma}_{\text {twin }}^{(\alpha)_{\max }}$. If $f^{(\alpha)} \geq f_{\text {th }}^{(\alpha)}$ has been satisfied in the grain in question and all of the slip systems of the grain have been subjected to the lattice rotation in the $\alpha$ twinning system during twinning, all of the slip systems are re-rotated to a specific detwinning orientation using the lattice rotation tensor $\left(\boldsymbol{R}^{\mathrm{tw}}\right)^{\mathrm{T}}$ when $\bar{\gamma}_{\mathrm{ut}}=\bar{\gamma}_{\mathrm{twin}}^{(\alpha) \max }$ is satisfied. If $f^{(\alpha)} \geq f_{\mathrm{th}}^{(\alpha)}$ has not been satisfied in the grain and the slip systems have not been subjected to the lattice rotation due to twinning, the slip systems are not rotated using the lattice rotation tensor $\left(\boldsymbol{R}^{\mathrm{tw}}\right)^{\mathrm{T}}$, even when $\bar{\gamma}_{\mathrm{ut}}=\bar{\gamma}_{\text {twin }}^{(\alpha) \max }$ is satisfied. The shear strain due to detwinning cannot arise in the grain after $\bar{\gamma}_{\mathrm{ut}}=\bar{\gamma}_{\text {twin }}^{(\alpha) \max }$ is satisfied, in any case.

The experimental results reported in the literature $[11,12]$ indicate that the initial strength of detwinning may be smaller than that of twinning. To simplify the model, in the present study, the initial strength of detwinning is regarded as an independent material parameter. Therefore, the kinematic hardening also is not taken into account for twinning and detwinning. The rate of hardening $h$ for detwinning is assumed to be the same as that of twinning.

The calibration of the material parameters, including $\gamma_{\text {ref }}$, used in the twinning model will be explained in the following sections. 


\section{Experimental Procedure}

Using a commercial rolled AZ31 Mg alloy sheet with a thickness of $0.8 \mathrm{~mm}$ (Osaka Fuji Corporation), stress-strain curves were obtained under various loading paths, such as monotonic tension and compression, compression-tension, tension-compression-tension, and cyclic loading-unloading, to determine the material parameters and to verify simulation results. The sheet material and the experimental procedures are the same as those used in our previous studies $[12,61]$. The material was annealed at $350^{\circ} \mathrm{C}$ for $1.5 \mathrm{~h}$ to obtain an $\mathrm{O}$ temper before the experiment. Specimens were machined parallel to the rolling direction. The experiment was performed at room temperature. A strain gauge (Kyowa Electronic Instruments Co., KFEM) was used to measure the strains during loading and unloading. The tests were performed at an initial strain rate of $0.0007 \mathrm{~s}^{-1}$. The experimental data were recorded by a data logger approximately every $10 \mathrm{~ms}$. To suppress buckling during in-plane uniaxial compression, comb-shaped dies were used to give compressive forces in the thickness direction of the specimen [12, 19, 61, 62]. The reader is referred to the literature $[19,61,62]$ for the details of the experimental procedure.

\section{Simulation Procedures}

\subsection{Material Modeling}

The finite-element model used in this study follows those used in Hama and Takuda [14, 19]. The schematic of the finite-element model used in the present study is shown in Figure 1. A cube was divided into 10 uniform 8-node isoparametric brick elements using selective reduced integration in each direction, producing a total of 1000 elements. The initial crystallographic orientations assigned to the model were artificially created to simulate the rolling texture of $\mathrm{Mg}$ alloy sheets $[22,23,26,63]$. The same initial crystallographic orientation was assigned to all the 
8 Gauss integration points in an element, thus the model had 1000 initial crystallographic orientations. Figure 2 shows the initial (0001) pole figure assigned to the model.

The finite-element model and number of initial crystallographic orientations described above were employed because these models give acceptable simulation results for the deformation behaviors of $\mathrm{Mg}$ alloy sheets, including the deformation during unloading under tension [19] and anisotropic work-hardening behavior [14].

A loading-unloading simulation under uniaxial compression along the rolling direction was performed. The planes $x=0, y=0$, and $z=0$ of the cube (Fig. 1) were fixed in the $x, y$, and $z$ directions, respectively, and the small displacement increments were given to the plane $x=l$ to compress and to unload the cube. It should be noted that the displacement increments during unloading were set to be five to ten times smaller than those during loading in order to avoid a numerical oscillation of the stress especially at the beginning of unloading.

\subsection{Material Parameters}

Isotropic elasticity with Young's modulus $E=42 \mathrm{GPa}$ and Poisson's ratio $v=0.3[7,12]$ were assumed. The reference strain rate was set to $\dot{\gamma}_{0}=0.001 \mathrm{~s}^{-1}$. The effect of the rate sensitivity exponent, $m$, on the unloading curve was examined under tension in our previous study [19], and $m=0.02$ gave the most appropriate results for the $\mathrm{Mg}$ alloy sheet. Therefore, $m=$ 0.02 was employed also in the present study. Following previous studies $[14,19,36]$, the latent-hardening parameters shown in Table 2 were adopted. The self-hardening parameters were set to $1 . \gamma_{\text {ref }}$ was set to 0.12 .

The hardening parameters used are shown in Table 3. These parameters were calibrated by modifying slightly the parameters used in Hama and Takuda [36] to fit experimental stress-strain 
curves under various loading paths. The identification of the hardening parameters was explained in detail in Hama and Takuda [19].

The simulated and experimental stress-strain curves under uniaxial tension and uniaxial compression are shown in Figure 3. The (0001) pole figures at a strain of 0.05 under tension and at a strain of -0.05 under compression that were obtained from the simulation are shown in Figure 4. A large dispersion of crystal orientations arose in the RD direction when the sheet was subjected to uniaxial compression, whereas the change in the texture was very small when the sheet was subjected to uniaxial tension. These tendencies are in good agreement with experimental observations [11].

Figure 5 shows the stress-strain curves under compression-tension and tension-compression-tension. The sigmoidal shape that arose during tension following compression is predicted well in the simulation results. As already explained in Hama and Takuda $[14,19]$, the texture evolutions predicted in the simulations also are qualitatively in good agreement with the experimental results [11]. The above results indicate that the assumption that the rate of hardening for detwinning is assumed to be the same as that of twinning may not be far removed from the reality.

\section{Results and Discussion}

\subsection{Macroscopic Unloading Curve}

Figure 6 shows an example of the stress-strain curves obtained by cyclic loading-unloading under compression. The variation of the instantaneous gradient $\mathrm{d} \sigma / \mathrm{d} \varepsilon$ during unloading calculated from the stress-strain curves is used to examine the nonlinear deformation during unloading in detail, as in Hama et al. [61] and Hama and Takuda [19]. Figures 7 and 8 show the 
results of the experiment and the simulation, respectively. The gradient was calculated using two data points for every 100 successive data points in the experiment and for every data point in the simulation. Therefore, in the experiment, the gradient at the end of unloading was not calculated because there is not enough number of data points. The strain at the beginning of unloading is hereafter termed the unloaded strain, $\varepsilon_{u}$. The legends give the absolute values of the unloaded strain. The horizontal and vertical axes of the figures are nondimensionalized using the stress at the beginning of unloading, $\sigma_{0}$, and Young's modulus, $E$, respectively.

The overall trend of the variation during unloading in the experiment (Fig. 7) is as follows. At the beginning of unloading, the gradient is larger than Young's modulus and decreases at a relatively large rate. Thereafter, the decreasing rate becomes moderate and this tendency is maintained until the end of unloading. These overall trends remain almost unchanged regardless of the unloaded strain. However, the decreasing rate at the beginning of unloading becomes large as the unloaded strain increases. Moreover, the magnitude of the overall decrease increases as the unloaded strain increases and the nondimensional gradient at the end of unloading eventually becomes less than 0.5 . Finally, the variation curve tends to saturate. As already reported in our previous study [61], the variation of the gradient observed under compression is clearly different from those observed under tension. For example, the amount of the overall decrease in the gradient is much larger under compression than it is under tension, which shows that the nonlinear deformation during unloading is much more pronounced under compression. Moreover, the variation curve saturates at a higher unloaded strain under compression than under tension.

In the simulation (Fig. 8), the overall trend of variation is not in good agreement with the experiment. For instance, in the simulation, the rapid decrease in the gradient at the beginning of unloading is much sharper than is observed experimentally, and there is a region where the 
nondimensional gradient maintains unity during unloading; this is not observed in the experimental result. However, in the simulation, the amount of overall decrease in the gradient increases as the unloaded strain increases; this is in good agreement with the experiment. In addition, in the simulation, the nondimensional gradient at the end of unloading eventually becomes less than 0.5 and the variation curve saturates at a higher unloaded strain under compression than under tension [61], as in the experiment. These tendencies are clearly different from that observed under tension. The above results show that the simulation results are qualitatively acceptable although they do not quantitatively agree with the experiment.

For comparison, the simulation result obtained in the cyclic loading-unloading test under tension is shown in Figure 9. It should be noted that the detwinning was considered when the simulation in Figure 9 was performed, whereas it had been neglected in our previous study [19]. Nonetheless, the result shown in Figure 9 is in close agreement with that reported in Hama and Takuda [19]. This shows that the effect of detwinning on the nonlinear deformation is negligible under tension, as had been presumed in Hama and Takuda [19]. This result is consistent with the results reported in Wang et al. [20].

\subsection{Activities of Slip and Twinning Systems}

In the following, the transition of the activities of each family of slip and twinning systems is used to examine the mechanism by which the nonlinear deformation during unloading is larger under compression than under tension. The activity of each family of slip or twinning systems, i, is evaluated by the plastic strain increment contributed by $i$, summed over all of the grains in the following form [19]:

$$
r_{\mathrm{i}}=\sum_{\mathrm{n}} \sum_{\mathrm{k}}\left|\Delta \gamma^{(\mathrm{n}, \mathrm{k})}\right|
$$


where $\mathrm{n}$ is the number of grains and $\mathrm{k}$ is the number of systems of the family $\mathrm{i}$. The twinning and detwinning are evaluated separately. As explained in Hama and Takuda [19], the relative activity [53], which is often used in crystal plasticity analyses, may not be suitable in the present study because the magnitude of the plastic strain increment is significantly different during loading and unloading. Therefore, the absolute value of the plastic strain increment [Eq. (6)] is used directly, instead of the relative value.

The transition of the plastic strain increment with absolute logarithmic strain during monotonic compression is shown in Figure 10. The absolute logarithmic strain-absolute true stress curve is also shown. At the beginning of the plastic deformation, the basal slip and the twinning are very active and the prismatic slip is also active. This tendency is maintained until an absolute strain of about 0.03 . Thereafter, the twinning activity starts decreasing, whereas the activities of the prismatic slip and the pyramidal-2 slip begin increasing. At the same time, the rate of work hardening in the stress-strain curve starts increasing and persists for a time. The detwinning activity is very small throughout the process. This result shows that, as already reported in the literature [29], the twinning activity is dominant at low strains, whereas several families of slip systems, including the pyramidal-2 slip, are active at high strains. The fluctuation observed in the activity of the basal slip occurs because of the lattice rotation due to twinning.

Figure 11 shows the evolution of the plastic strain increment during cyclic loading-unloading with the accumulated absolute strain. The sheet was unloaded periodically at every 0.01 strain increment. Figure 12 shows the enlarged figures of the designated shaded areas, $\mathrm{A}$ and $\mathrm{B}$, in Figure 11, during which the sheet was unloaded at strains of 0.05 and 0.07 , respectively. When the unloading of the sheet begins, the activities of all of the systems vanish at once; immediately after, the basal slip is activated. The basal slip is activated exclusively during 
unloading at low strains. However, at high strains, only the basal slip is activated until the middle stage of unloading, whereas detwinning is activated also at the later stage. Interestingly, the activity of the basal slip becomes large as the unloaded strain increases. The above results show that the nonlinear deformation during unloading is governed by the activity of the basal slip at low strains, whereas it is controlled by the activities of both the basal slip and detwinning at high strains.

The observation that the activity of the basal slip is large during unloading under compression is very similar to the result observed under tension [19]. As explained in Hama and Takuda [19], the basal slip may be active during unloading under tension because of its low strength compared to that of the prismatic slip, which governs the deformation during loading. A similar mechanism may explain the results obtained under compression, as follows: The stress level during loading is determined primarily by the twinning because the twinning activity is dominant during loading at low strains. As a result, the basal slip can be activated easily during unloading at low strains because the strength of the basal slip is lower than that of the twinning (Table 3). However, at high strains, the twinning as well as the prismatic slip and the pyramidal-2 slip are activated during loading; hence, the stress level is much higher than that at low strains, as shown in Figure 6. Consequently, both the basal slip and the detwinning - which are weaker than the nonbasal slip — are activated during unloading. The detwinning may be activated later than the basal slip (Fig. 12) because the strength of the detwinning is larger than that of the basal slip.

The above results and discussion suggest that the nonlinear deformation during unloading may be larger under compression than under tension because of the detwinning activity. This result is consistent with the experimental and numerical observations reported in the literature $[17,18,20,61]$. 


\subsection{Effect of Detwinning}

If the above-mentioned mechanism is correctly described by the model, the decrease in the instantaneous gradient during unloading may become much smaller when detwinning is not taken into account in the simulation. To confirm this presumption, we performed a cyclic loading-unloading simulation that did not consider the detwinning model. The variations of the instantaneous gradient during unloading obtained by the simulation are shown in Figure 13. Clearly, the decrease in the gradient in the later stage of unloading is smaller than the original result (Fig. 8), indicating that detwinning plays an important role in the nonlinear deformation, particularly in the later stage of unloading. This result is consistent with the detwinning activity shown in Figure 12.

However, the decrease in the instantaneous gradient in the middle stage of unloading remains pronounced and is larger than that under tension (Fig. 9), even when detwinning is taken into account. As a consequence, the overall decrease is still larger than that observed under tension (Fig. 9). Because the decrease in the middle stage is induced primarily by the activity of the basal slip, as shown in Figure 12, other mechanisms in addition to detwinning would induce the pronounced nonlinear deformation under compression.

\subsection{Effect of Lattice Rotation}

It is established that, as shown in Figure 4, the texture changes significantly during compression compared to during tension because of twinning activity. Clearly, the inhomogeneity of the material is more pronounced as the sheet is compressed and the twinning is activated. In our previous study [19], numerical experiments showed that a sheet with random 
orientations exhibited a larger nonlinear deformation during unloading under tension than a sheet with a rolling texture. This difference in the nonlinear deformation during unloading arose because the activity of the basal slip during unloading was enhanced by the inhomogeneity of the material. A similar explanation may be given for the difference obtained under tension and compression, particularly at high strains: the nonlinear deformation during unloading may be more pronounced under compression because the activity of the basal slip may become more pronounced owing to the dispersion of crystallographic orientations. This presumption is consistent with the observation that the activity of the basal slip during unloading becomes large as the unloaded strain increases (Fig. 11).

If this presumption is correct, the decrease in the gradient would lessen when the twin reorientation is not considered in the simulation. To confirm this, a cyclic loading-unloading simulation was performed that ignored both detwinning and the twin reorientation. It should be noted that twinning and detwinning were treated merely as slip in this simulation, as in Graff et al. [23]. The variations in the instantaneous gradient during unloading that were obtained in this simulation are shown in Figure 14. As we expected, the decrease in the gradient in the middle stage is smaller than in the simulation that ignores detwinning (Fig. 13). Figure 15 shows the transition of the plastic strain increment during unloading. The unloaded strains are 0.05 and 0.07 . Compared to the original results (Fig. 12), the total amount of plastic strain induced by the basal slip is smaller and this tendency is more pronounced at the unloaded strain of 0.07 than that at the unloaded strain of 0.05 . The above results indicate that the more pronounced nonlinear deformation during unloading under compression than under tension is the result of two factors: 1) detwinning and 2) the increased basal slip induced by the dispersion of crystallographic orientations, which is the result of twinning during loading. Wang et al. [20] did not mention the 
effect of texture change on the nonlinear deformation during unloading. This may be because they examined the deformation only at low strains, at which the effect of texture change might not be significant.

It should be noted that the overall decrease in the gradient observed in the simulation that ignores both detwinning and the twin reorientation (Fig. 14) is still slightly larger than that observed under tension (Fig. 9). This indicates that other mechanisms, in addition to those noted above, may be at play. For example, the stress state in each grain may be significantly different under compression and under tension. The strain in the RD direction is determined by the boundary conditions, as explained in section 4.1. The through-thickness strain may arise more easily under compression than under tension, because the activities of both the twinning and the pyramidal-2 slip are larger under compression than under tension. This clearly shows that the strain distribution differs significantly under tension and under compression and indicates that the 3-dimensional stress state in each grain, including factors such as the distribution in each direction and the magnitude of each component, may also differ. This difference in the stress state in each grain may affect the nonlinear deformation during unloading. Because the plastic deformation examined in the present study is relatively large, contraction twinning [64-66] may also affect the nonlinear deformation during unloading. This will be the subject of our future work.

\section{Conclusions}

In the present study, we performed a simulation of the loading-unloading process in a rolled $\mathrm{Mg}$ alloy sheet under in-plane compression using a crystal plasticity finite-element method that 
considered detwinning and we examined the effect of twinning and detwinning on the deformation during unloading. The variation with stress of the instantaneous gradient during unloading was investigated for a macroscopic stress-strain curve and the activity of each family of slip or twinning systems was examined for mesoscopic deformation. We conclude the following:

(1) Concerning the macroscopic stress-strain curve, the simulation results are in good agreement with the following experimental results: the amount of decrease in the instantaneous gradient increases as the unloaded strain increases and is much larger than that under tension, and the variation curve saturates at a higher unloaded strain under compression than under tension. These results show that the present simulation results are qualitatively acceptable.

(2) A numerical experiment shows that the nonlinear deformation during unloading is less pronounced when detwinning is not taken into account. This result shows that the activity of detwinning during unloading plays an important role in the nonlinear deformation during unloading. However, the nonlinear deformation during unloading is still larger than under tension even when detwinning is not considered. This indicates that other mechanisms may induce the nonlinear deformation during unloading under compression.

(3) The twin reorientation that arises during loading may induce the nonlinear deformation during unloading. This is because the activity of the basal slip during unloading may become more pronounced because of the dispersion of orientations caused by twinning. A numerical experiment in which both the detwinning and the twin reorientation are not considered shows that the nonlinear deformation during unloading becomes smaller, as expected. It can be concluded from the above results that the nonlinear deformation during unloading is more pronounced under compression than under tension, because of 2 factors: detwinning activity 
and an increase in the activity of the basal slip induced by the dispersion of crystallographic orientations, caused by twinning activity during loading.

Acknowledgements

This work was partially supported by KAKENHI (23760697: Grant-in-Aid for Young Scientist (B)) in Japan and the Amada Foundation for metal work technology.

\section{REFERENCES}

[1] B.L. Mordike, T. Ebert, Materials Science and Engineering A, 302 (2001), 37-45.

[2] M.K. Kulekci, International Journal of Advanced Manufacturing Technology, 39 (2008), $851-865$.

[3] E. Doege, K. Droder, Journal of Materials Processing Technology, 115 (2001), 14-19.

[4] F.K. Chen, T.B. Huang, C.K. Chang, International Journal of Machine Tools \& Manufacture, 43 (2003), 1553-1559.

[5] Y.S. Lee, M.C. Kim, S.W. Kim, Y.N. Kwon, S.W. Choi, J.H. Lee, Journal of Materials Processing Technology 187-188 (2007), 103-107.

[6] H.J. Kim, S.C. Choi, K.T. Lee, H.Y. Kim, Materials Transactions, 49-5(2008), 1112-1119.

[7] T. Hama, Y. Kariyazaki, K. Ochi, H. Fujimoto, H. Takuda, Materials Transactions, 51-4 (2010), 685-693.

[8] Q. Zhang, F. Xiao, H. Guo, C. Li, L. Gao, X. Guo, W. Han, A.B. Bondarev, Journal of Materials Processing Technology, 210 (2010), 323-329.

[9] Z. Meng, S. Huang, J. Hu, W. Huang, Z. Xia, Journal of Materials Processing Technology, $211(2011), 863-867$. 
[10] M. Nebebe Mekonen, D. Steglich, J. Bohlen, D. Letzig, J. Mosler, Materials Science and Engineering A, 540 (2012), 174-186.

[11] X.Y. Lou, M. Li, R.K. Boger, S.R. Agnew, R.H. Wagoner, International Journal of Plasticity, 23 (2007), 44-86.

[12] T. Hama, Y. Kariyazaki, N. Hosokawa, H. Fujimoto, H. Takuda, Materials Science and Engineering A, 551 (2012), 209-217.

[13] M.O. Andar, T. Kuwabara, D. Steglich, Materials Science and Engineering A, 549 (2012), 82-92.

[14] T. Hama, H. Takuda, Computational Materials Science, 51 (2012), 156-164.

[15] C.H. Cáceres, T. Sumitomo, M. Veidt, Acta Materialia, 51 (2003), 6211-6218.

[16] G.E. Mann T. Sumitomo, C.H. Cáceres, J.R. Griffiths, Materials Science and Engineering A, 456 (2007), 138-146.

[17] Y. Li, M. Enoki, Materials Transactions, 49 (2008), 1800-1805.

[18] O. Muránsky, D.G. Carr, P. Sittner, E.C. Oliver, International Journal of Plasticity, 25 (2009), 1107-1127.

[19] T. Hama, H. Takuda, International Journal of Plasticity, 27 (2011), 1072-1092.

[20] H. Wang, P.D. Wu, J. Wang, International Journal of Plasticity, in press.

[21] A. Staroselsky, L. Anand, International Journal of Plasticity, 19 (2003), 1843-1864.

[22] S.R. Agnew, Ö. Duygulu, International Journal of Plasticity, 21 (2005), 1161-1193.

[23] S. Graff, W. Brocks, D. Steglich, International Journal of Plasticity, 23 (2007), 1957-1978.

[24] B. Clausen, C.N. Tomé, D.W. Brown, S.R. Agnew, Acta Materialia, 56 (2008), 2456-2468.

[25] S.-H. Choi, D.H. Kim, H.W. Lee, B.S. Seong, K. Piao, R.H. Wagoner, Materials Science and Engineering A, 526 (2009), 38-49. 
[26] T. Mayama, K. Aizawa, Y. Tadano, M. Kuroda, Computational Materials Science, 47 (2009), 448-455.

[27] G. Proust, C.N. Tomé, A. Jain, S.R. Agnew, International Journal of Plasticity, 25 (2009), 861-880.

[28] J. Lévesque, K. Inal, K.W. Neale, R.K. Mishra, International Journal of Plasticity, 26 (2010), 65-83.

[29] H. Wang, B. Raeisinia, P.D. Wu, S.R. Agnew, C.N. Tome, International Journal of Solids and Structures, 47 (2010), 2905-2917.

[30] S.-H. Choi, D.W. Kim, B.S. Seong, A.D. Rollett, International Journal of Plasticity, 27 (2011), 1702-1720.

[31] A. Fernandez, M.T.P. Prado, Y. Wei, A. Jerusalem, International Journal of Plasticity, 27 (2011), 1739-1757.

[32] C. Guillemer, M. Clavel, G. Cailletaud, International Journal of Plasticity, 27 (2011), 2068-2084.

[33] T. Mayama, M. Noda, R. Chiba, M. Kuroda, International Journal of Plasticity, 27 (2011), 1916-1935.

[34] D. Steglich, W. Brocks, J. Bohlen, International Journal of Material Forming, 4 (2011), 243-253.

[35] H. Wang, P.D. Wu, K.P. Boyle, K.W. Neale, International Journal of Solids and Structures, 48 (2011), 1000-1010.

[36] T. Hama, H. Takuda, Steel Research International, Special Edition (2012), 1115-1118.

[37] M. Homayonifar, J. Mosler, International Journal of Plasticity, 28 (2012), 1-20.

[38] B. Hutchinson, J. Jain, M.R. Barnet, Acta Materialia, 60 (2012), 5391-5398. 
[39] Q. Ma, H. El Kadiri, A.L. Oppedal, J.C. Baird, B. Li, M.F. Horstemeyer, S.C. Vogel, International Journal of Plasticity, 29 (2012), 60-76.

[40] A.L. Oppedal, H. El Kadiri, C.N. Tome, G.C. Kaschner, S.C. Vogel, J.C. Baird, International Journal of Plasticity, 30-31 (2012), 41-61.

[41] A. Ostapovets, P. Šedá, A. Jäger, P. Lejcek, International Journal of Plasticity, 29 (2012), $1-12$.

[42] D. Steglich, Y. Jeong, M.O. Andar, T. Kuwabara, International Journal of Solids and Structures, 49 (2012), 3551-3561.

[43] J. Zhang, S.P. Joshi, Journal of the mechanics and physics of solids, 60 (2012), 945-972.

[44] M. Kawka, A. Makinouchi, Journal of Materials Processing Technology, 50 (1995), 105-115.

[45] T. Hama, T. Nagata, C. Teodosiu, A. Makinouchi, H. Takuda, International Journal of Mechanical Sciences, 50 (2008), 175-192.

[46] D. Pierce, R.J. Asaro, A. Needleman, Acta Metallurgica, 31 (1983), 1951-1976.

[47] R.J. Asaro, A. Needleman, Acta Metallurgica, 33 (1985), 923-953.

[48] Y. Yamada, N. Yoshimura, T. Sakurai, International Journal of Mechanical Sciences, 10 (1968), 343-54.

[49] J. Harder, International Journal of Plasticity, 15 (1999), 605-624.

[50] C.L. Xie, S. Ghosh, M. Groeber, Journal of Engineering Materials and Technology. Transactions of the ASME, 126 (2004), 339-352.

[51] E. Nakamachi, N.N. Tam, H. Morimoto, International Journal of Plasticity, 23 (2007), 450-489.

[52] P. Van Houtte, Acta Metallurgica, 26 (1978), 591-604. 
[53] C.N. Tomé, R.A. Lebensohn, U.F. Kocks, Acta Metallurgica et Materialia, 39 (1991), $2667-2680$.

[54] S.R. Kalidindi, Journal of the Mechanics and Physics of Solids, 46 (1998), 267-290.

[55] H. El Kadiri, A.L. Oppedal, Journal of the Mechanics and Physics of Solids, 58 (2010), 613-624.

[56] R. Glüge, A. Bertram, T. Böhlke, E. Specht, Zeitschrift für Angewandte Mathematik und Mechanik, 90-7 (2010), 565-594.

[57] M. Homayonifar, J. Mosler, International Journal of Plasticity, 27 (2011), 983-1003.

[58] H. Abdolvand, M.R. Daymond, Acta Materialia, 60 (2012), 2240-2248.

[59] H. Wang, P.D. Wu, C.N. Tome, J. Wang, Materials Science and Engineering A, 555 (2012), 93-98.

[60] G.Y. Chin, W.F. Hosford, D.R. Mendorf, Proceedings of the Royal Society A, 309 (1969), 433-456.

[61] T. Hama, K. Ochi, N. Kitamura, H. Fujimoto, H. Takuda, Steel Research International, Special Edition (2011), 1054-1059.

[62] T. Kuwabara, Y. Kumano, J. Ziegelheim, I. Kurosaki, International Journal of Plasticity, 25 (2009), 1759-1776.

[63] Y. Chino, K. Sassa, A. Kamiya, M. Mabuchi, Materials Science and Engineering A, 473 (2008), 195-200.

[64] M.R. Barnett, Materials Science and Engineering A, 464 (2007), 8-16.

[65] A. Izadbakhsh, K. Inal, R.K. Mishra, Computational Materials Science, 50 (2010), 571-585.

[66] A. Izadbakhsh, K. Inal, R.K. Mishra, M. Niewczas, Computational Materials Science, 50 (2011), 2185-2202. 
Figure and table captions

Fig. 1 Finite-element model used in the simulation.

Fig. 2 (0001) pole figure used in the simulation model with a rolling texture.

Fig. 3 Stress-strain curves under monotonic loading. (a) Uniaxial tension and (b) uniaxial compression.

Fig. 4 (0001) pole figures. (a) Result at 0.05tensile strain, and (b) result at 0.05 compressive strain.

Fig. 5 Stress-strain curves under cyclic loading. (a) Compression-tension and (b) tension-compression-tension.

Fig. 6 Stress-strain curves during cyclic loading-unloading obtained by simulation and experiment.

Fig. 7 Variations in instantaneous gradient during unloading obtained by the experiment in the unloaded strain ranges: (a) from 0.0045 to 0.04 and (b) from 0.05 to 0.08 .

Fig. 8 Variations in instantaneous gradient during unloading obtained by the simulation in the unloaded strain ranges: (a) from 0.001 to 0.04 and (b) from 0.05 to 0.09 .

Fig. 9 Variations in instantaneous gradient during unloading under tension obtained by the simulation in the unloaded strain ranges: (a) from 0.001 to 0.008 and (b) from 0.009 to 0.03 . Fig. 10 Plastic strain increment contributed by families of slip and twinning systems during uniaxial compression.

Fig. 11 Plastic strain increment contributed by families of slip systems during cyclic loading-unloading in the accumulated absolute strain ranges: (a) from 0.04 to 0.08 and (b) from 0.08 to 0.13 . Shaded areas correspond to unloading processes. 
Fig. 12 Enlarged figures of designated shaded areas in Fig. 11. Enlarged figure of (a) A (unloaded strain of 0.05) and (b) B (unloaded strain of 0.07) .

Fig. 13 Variations in instantaneous gradient during unloading obtained by the simulation without considering detwinning in the unloaded strain ranges: (a) from 0.001 to 0.04 and (b) from 0.05 to 0.09 .

Fig. 14 Variations in instantaneous gradient during unloading obtained by the simulation without considering detwinning and twin reorientation in the unloaded strain ranges: (a) from 0.001 to 0.04 and (b) from 0.05 to 0.09 .

Fig. 15 Evolution of the plastic strain increment during unloading. Unloaded strains of (a) 0.05 and (b) 0.07 .

Table 1. Plane normal and slip direction vectors of slip and twinning systems used in the present study.

Table 2. Latent-hardening parameters qab used in the present study (Graff et al., 2007) .

Table 3. Calibrated material parameters in Eqs. (4) and (5). 


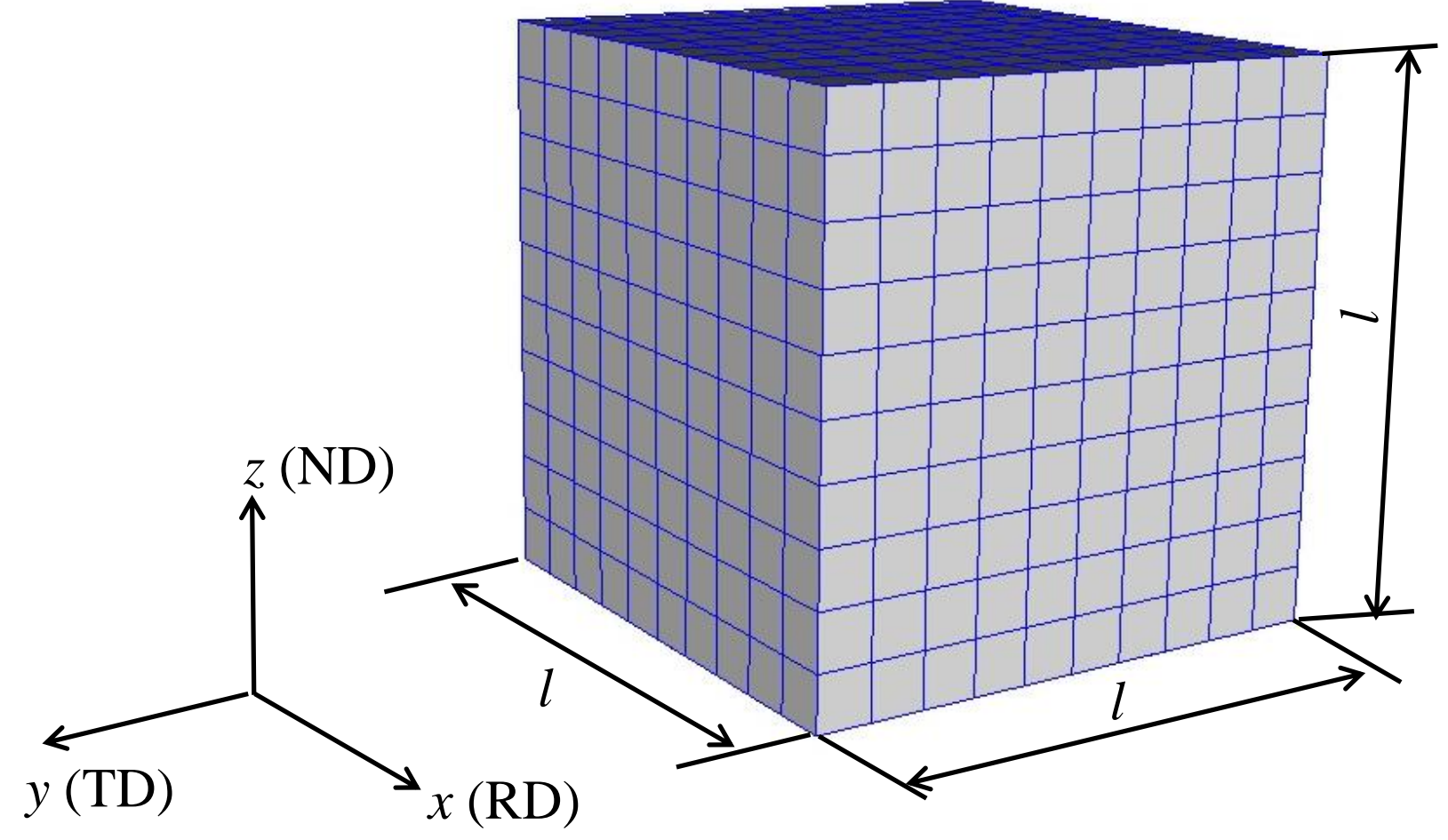

Fig. 1 Finite-element model used in the simulation. 


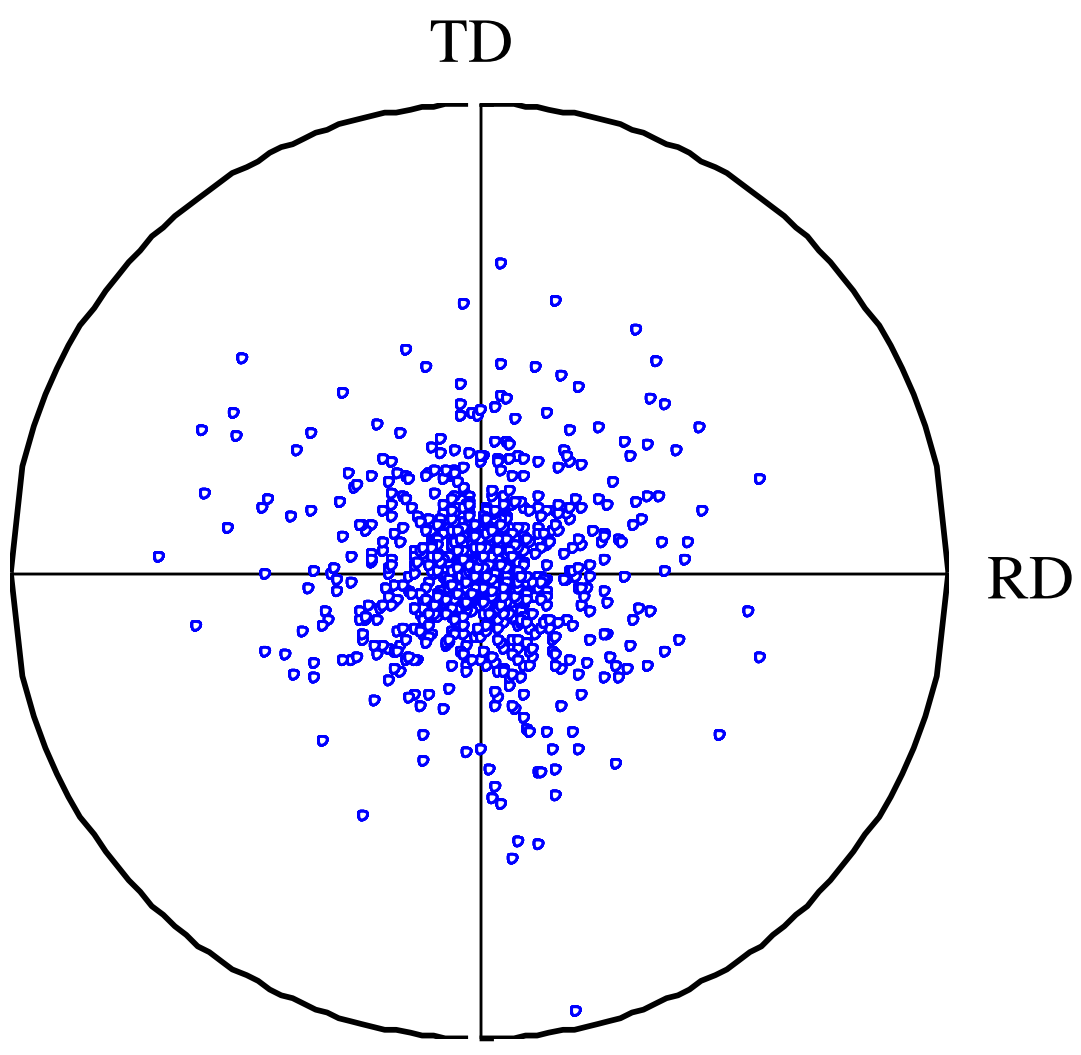

Fig. 2 (0001) pole figure used in the simulation model with a rolling texture. 


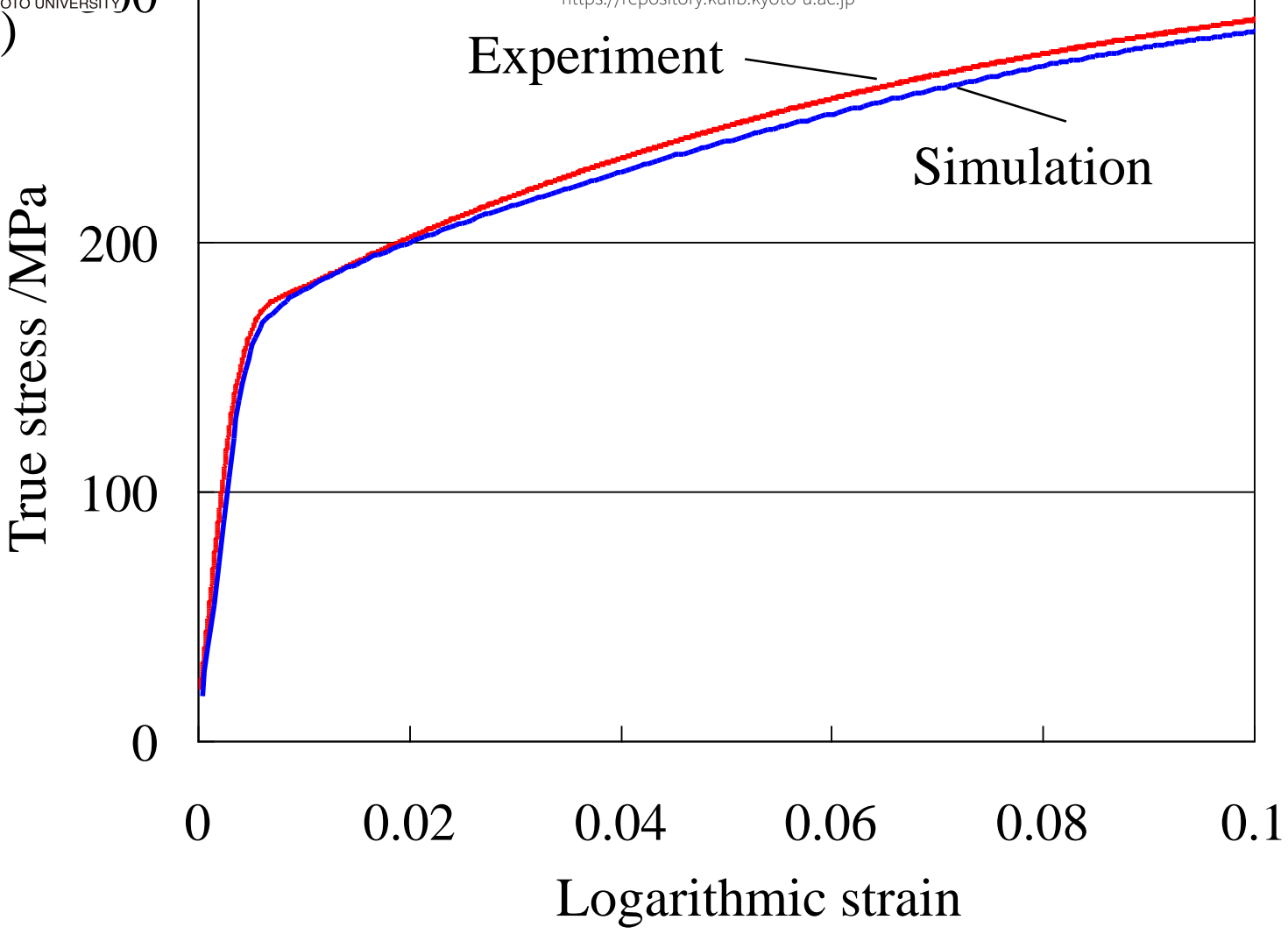

Logarithmic strain
(b) -0.1
$-0.08$
$-0.06$
$-0.04$
$-0.02$
0

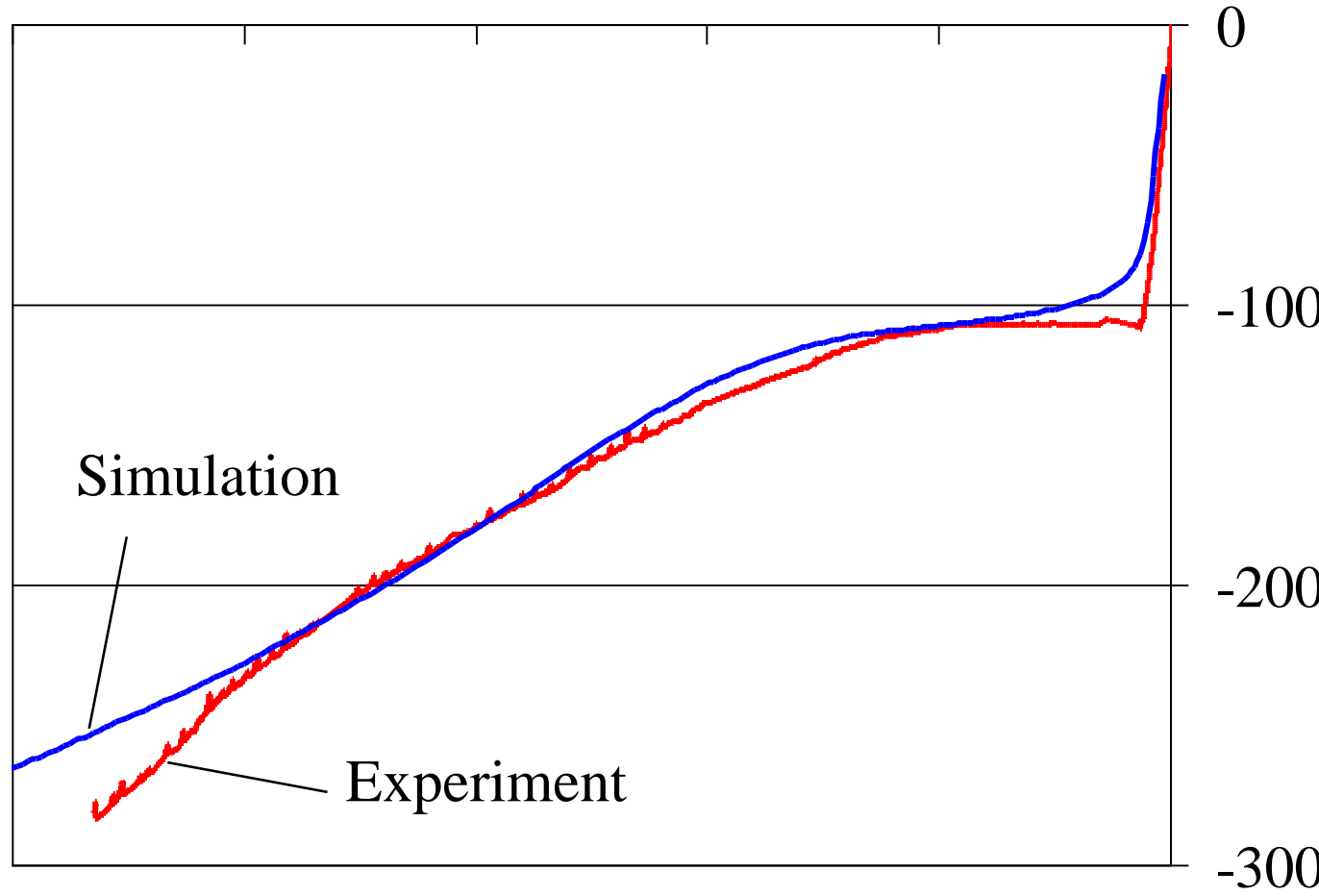

Fig. 3 Stress-strain curves under monotonic loading. (a) Uniaxial tension and (b) uniaxial compression. 


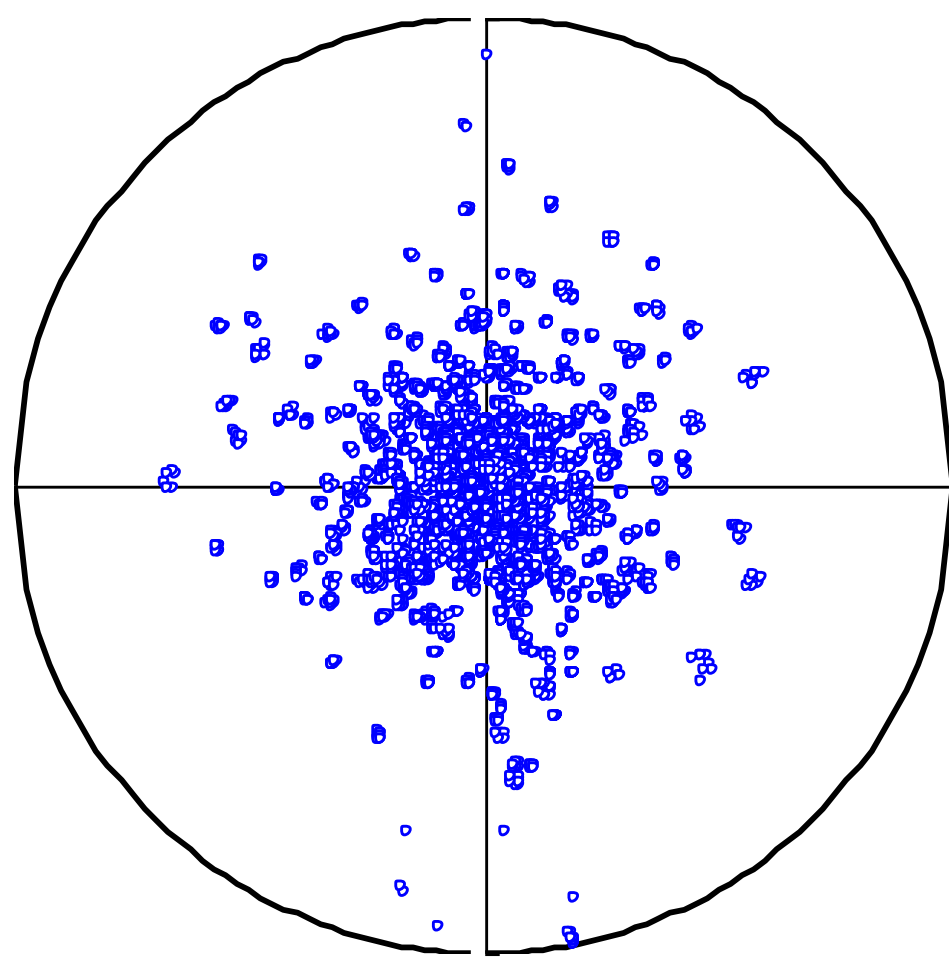

$\mathrm{RD}$

(b)

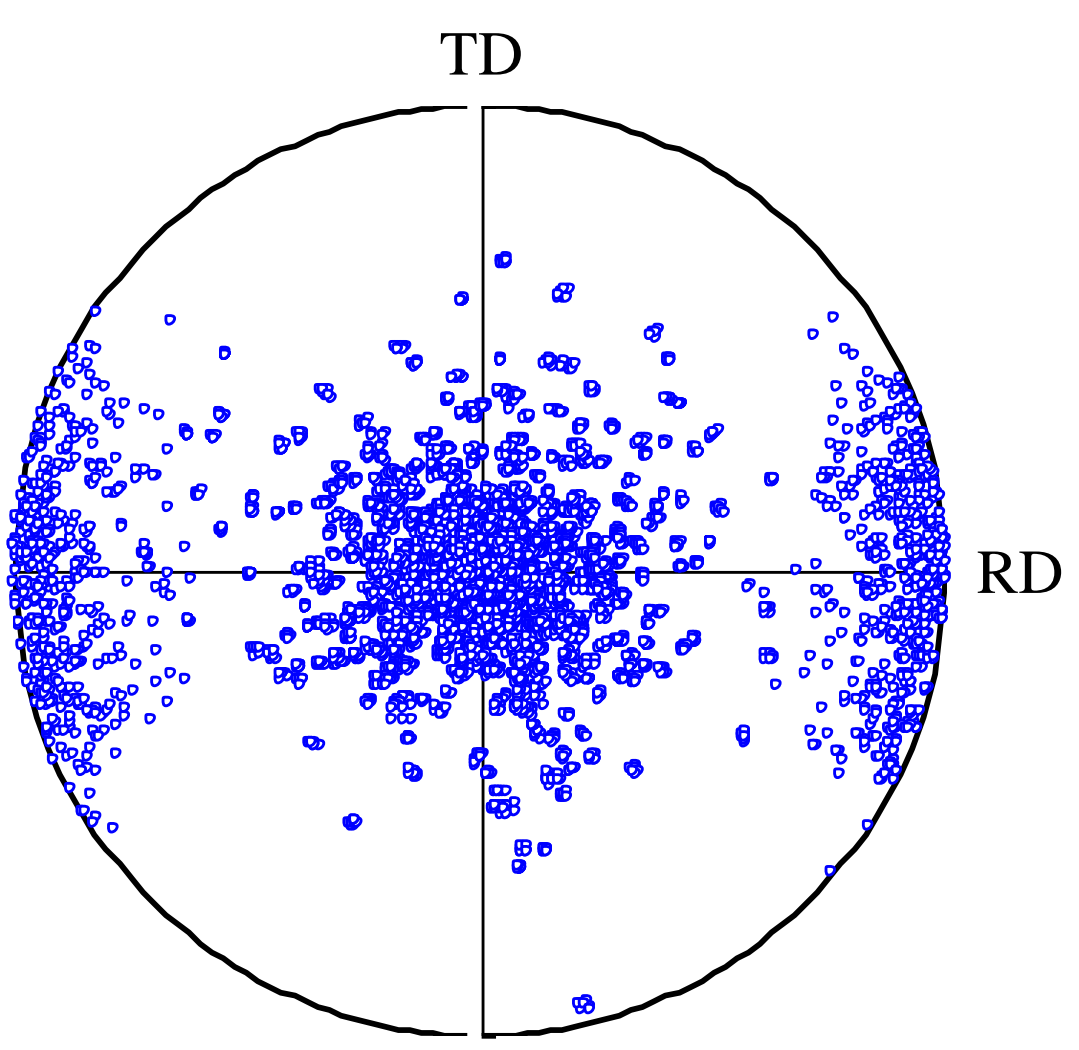

Fig. 4 (0001) pole figures. (a) Result at 0.05tensile strain, and (b) result at 0.05 compressive strain. 
(a)

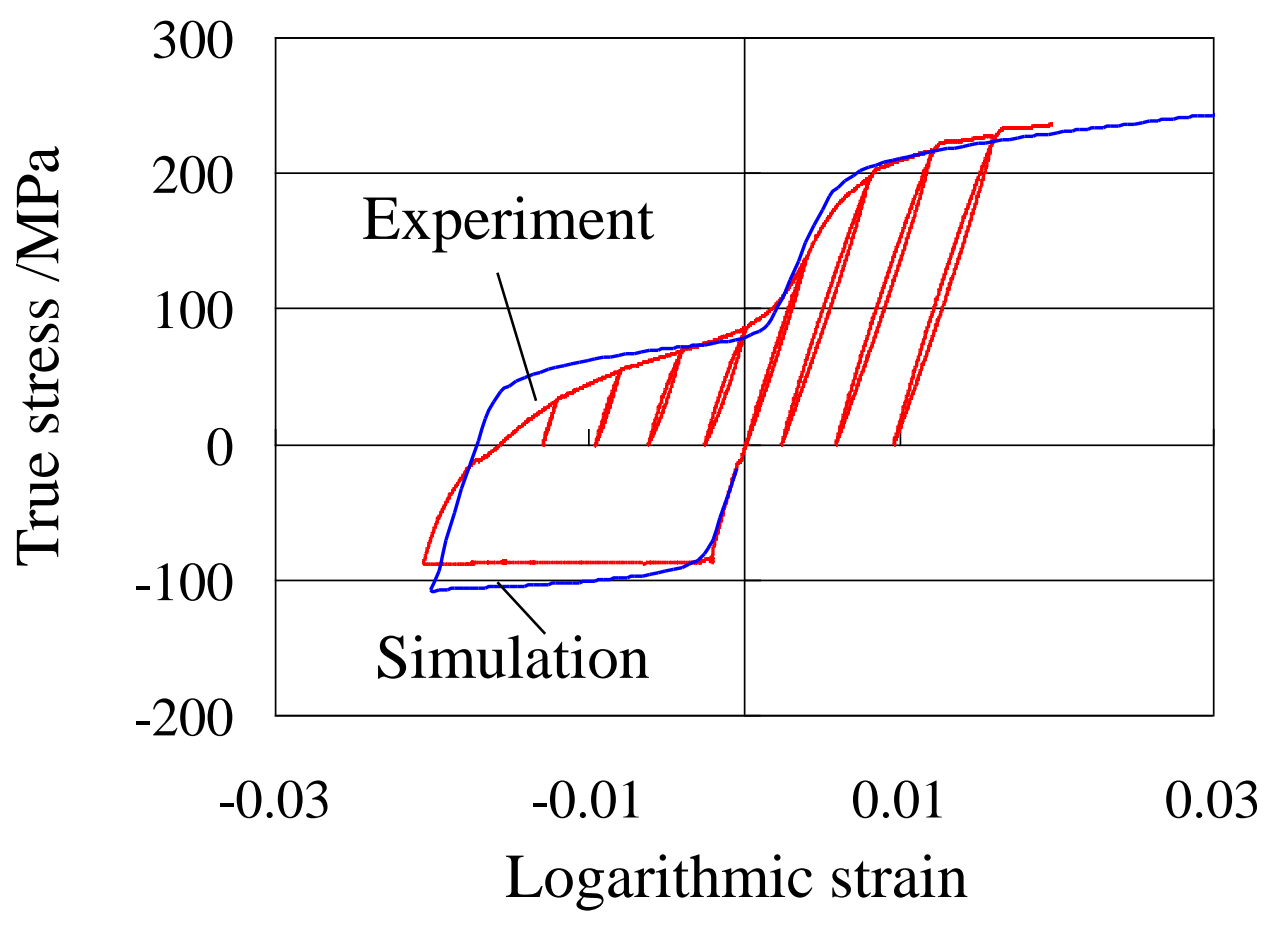

(b)

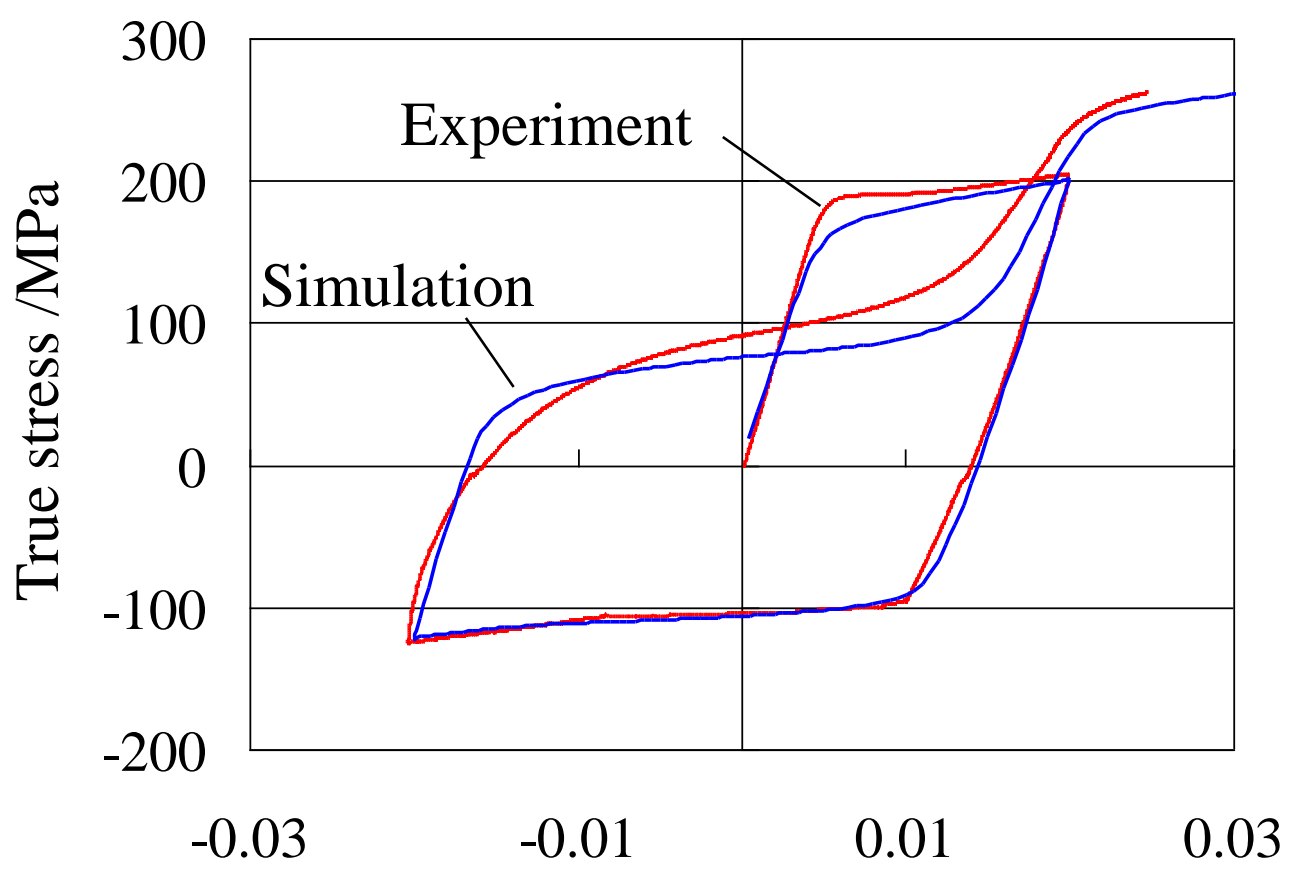

Logarithmic strain

Fig. 5 Stress-strain curves under cyclic loading. (a) Compression-tension and (b) tension-compressiontension. 
Logarithmic strain

$\begin{array}{llllll}-0.1 & -0.08 & -0.06 & -0.04 & -0.02 & 0\end{array}$

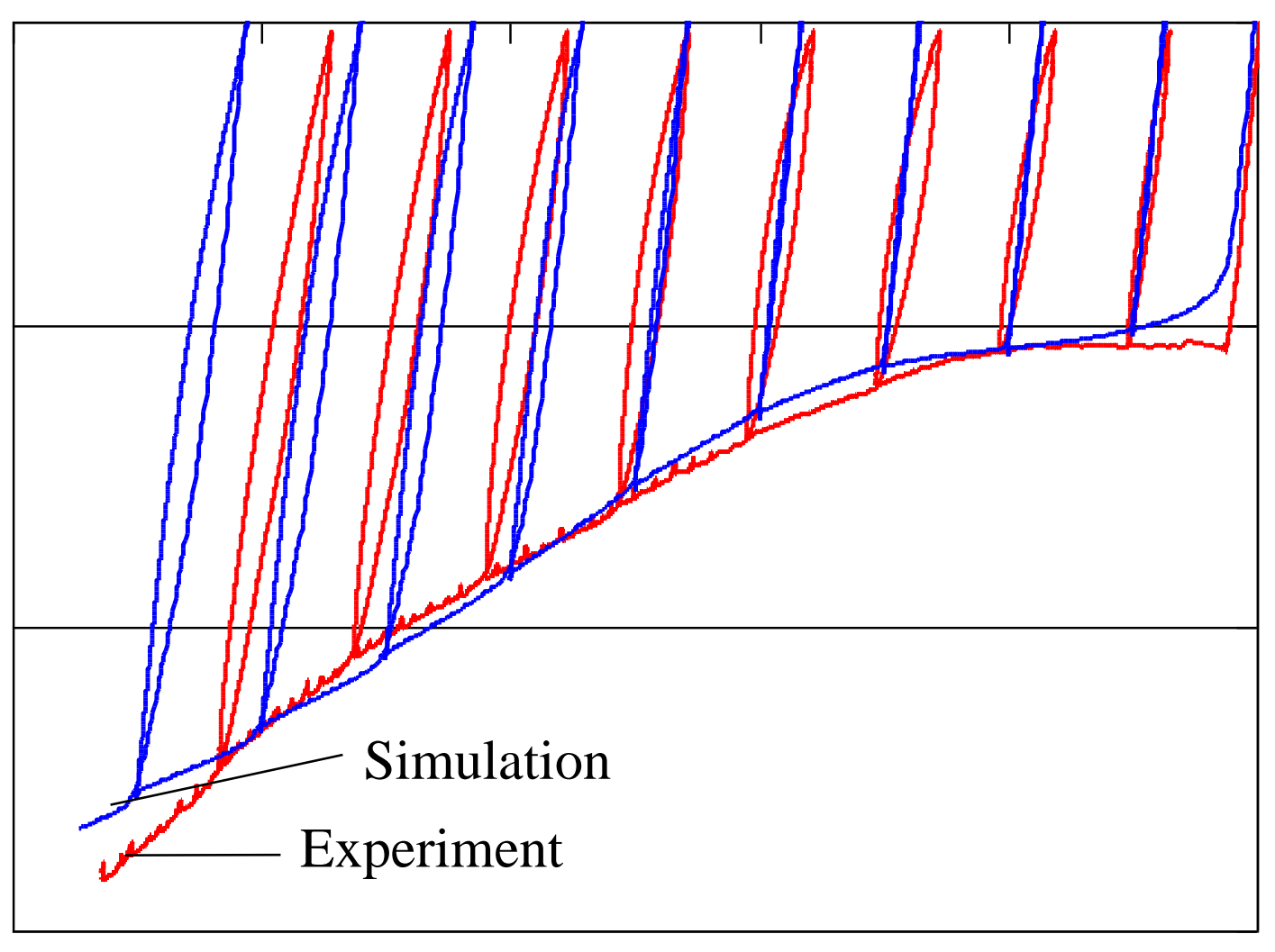

0

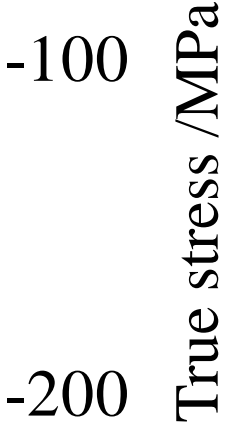

$-300$

Fig. 6 Stress-strain curves during cyclic loadingunloading obtained by simulation and experiment. 
(a)

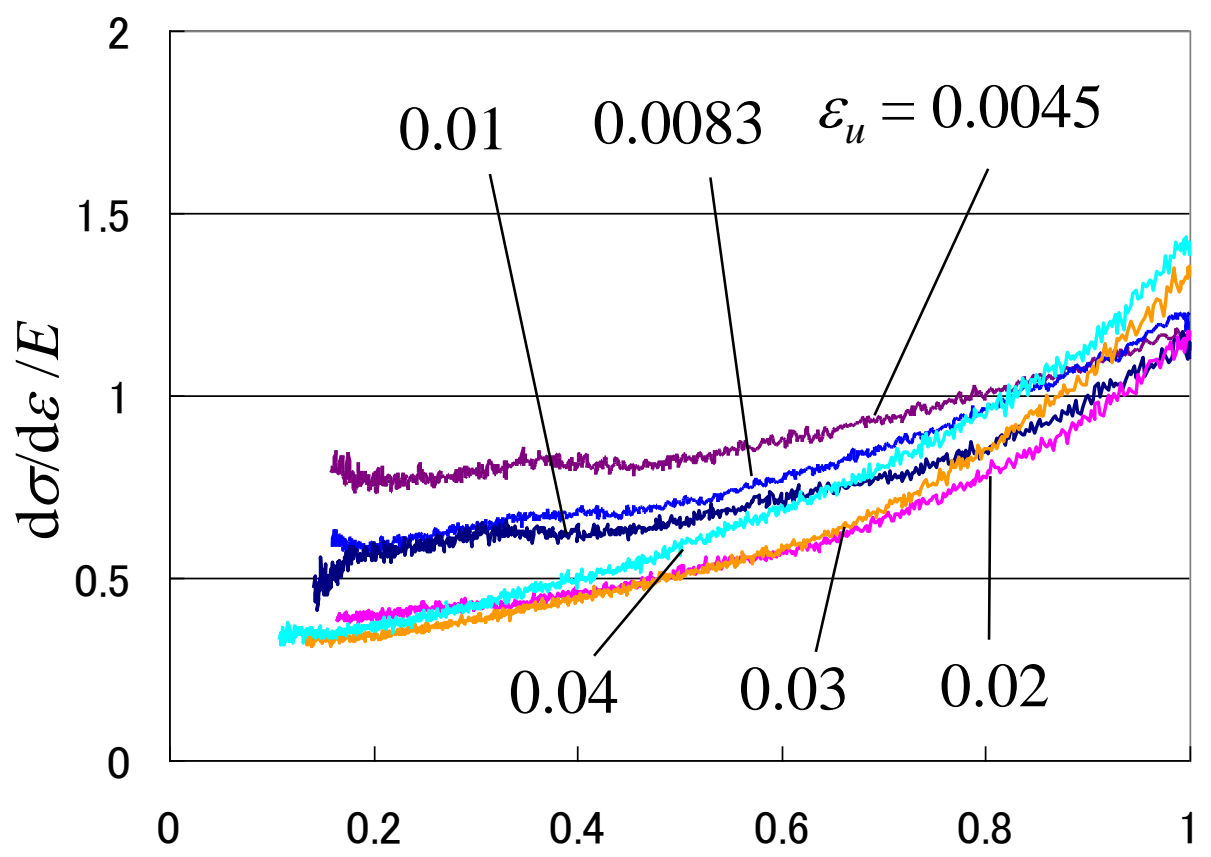

Dimensionless stress $\sigma / \sigma_{0}$

(b)

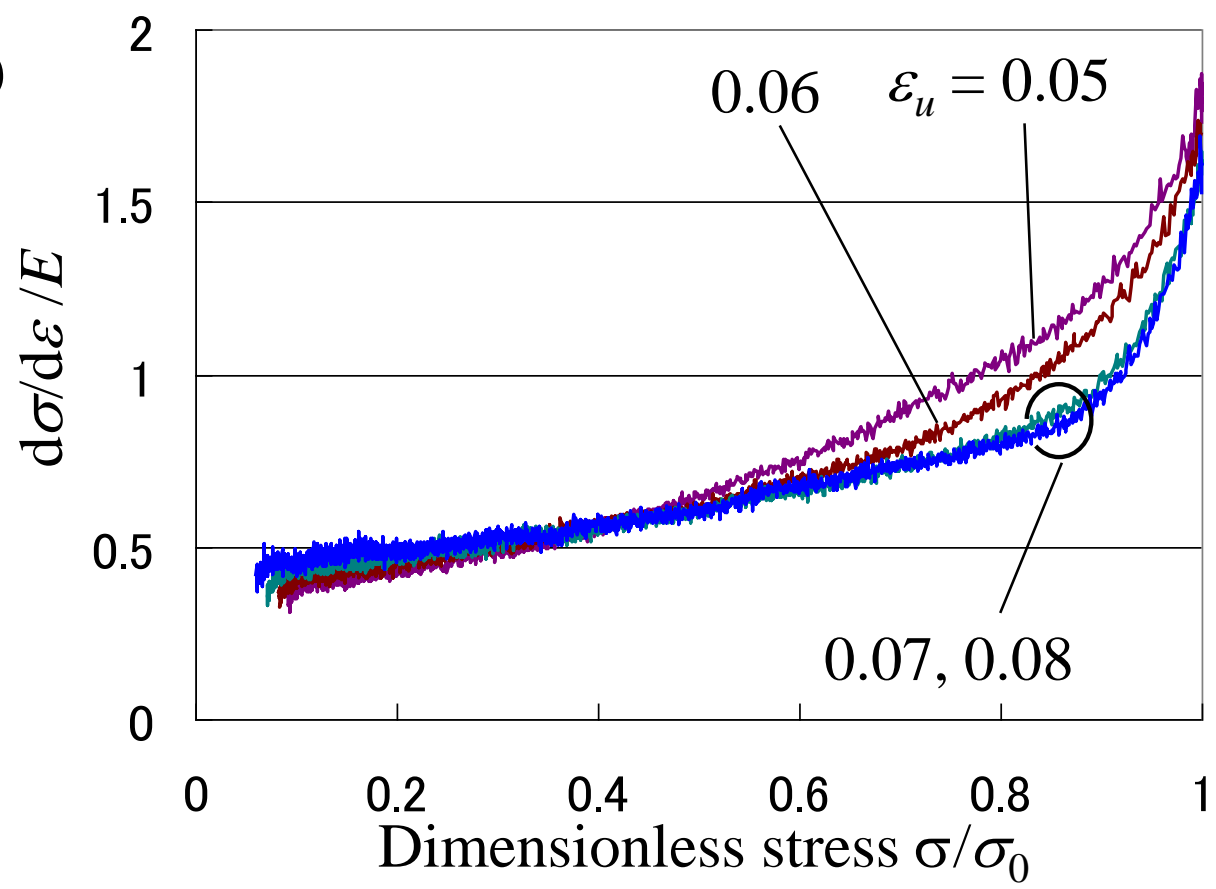

Fig. 7 Variations in instantaneous gradient during unloading obtained by the experiment in the unloaded strain ranges: (a) from 0.0045 to 0.04 and (b) from 0.05 to 0.08 . 
(a)

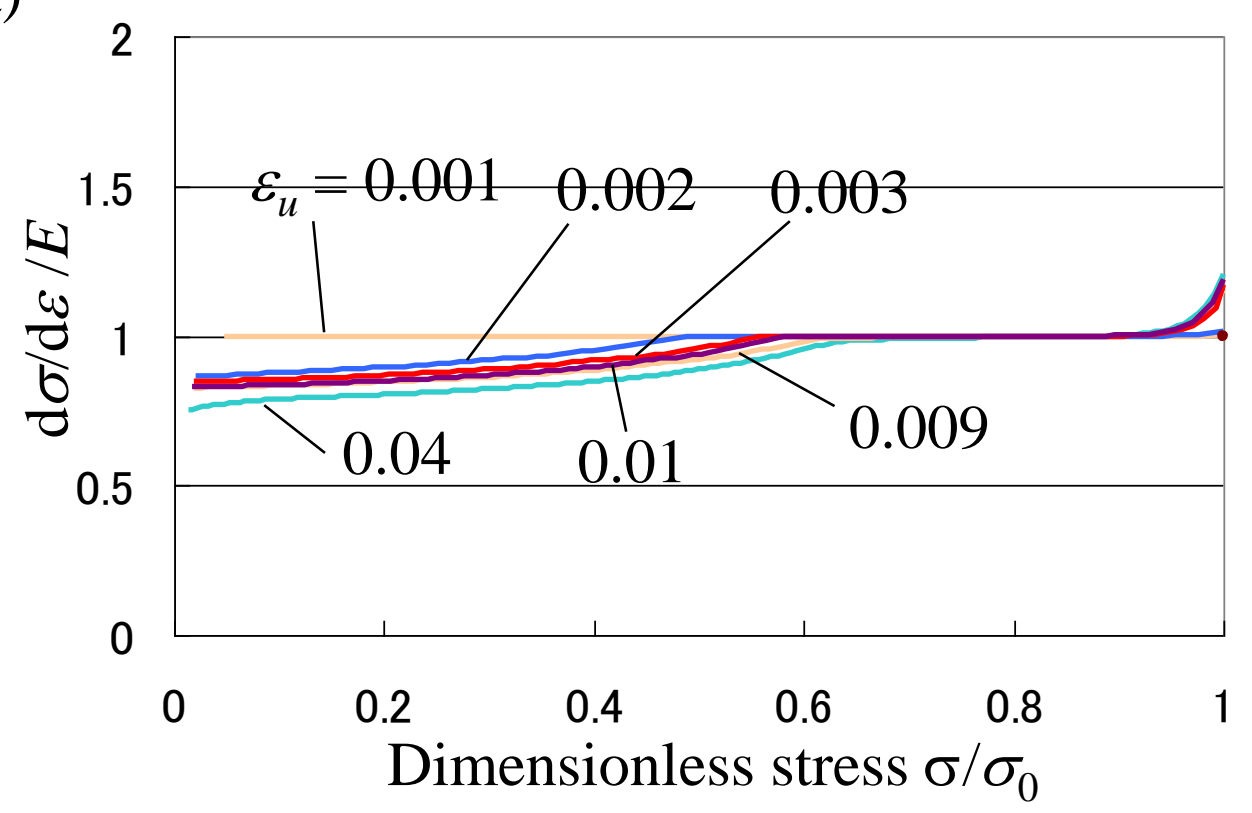

(b)

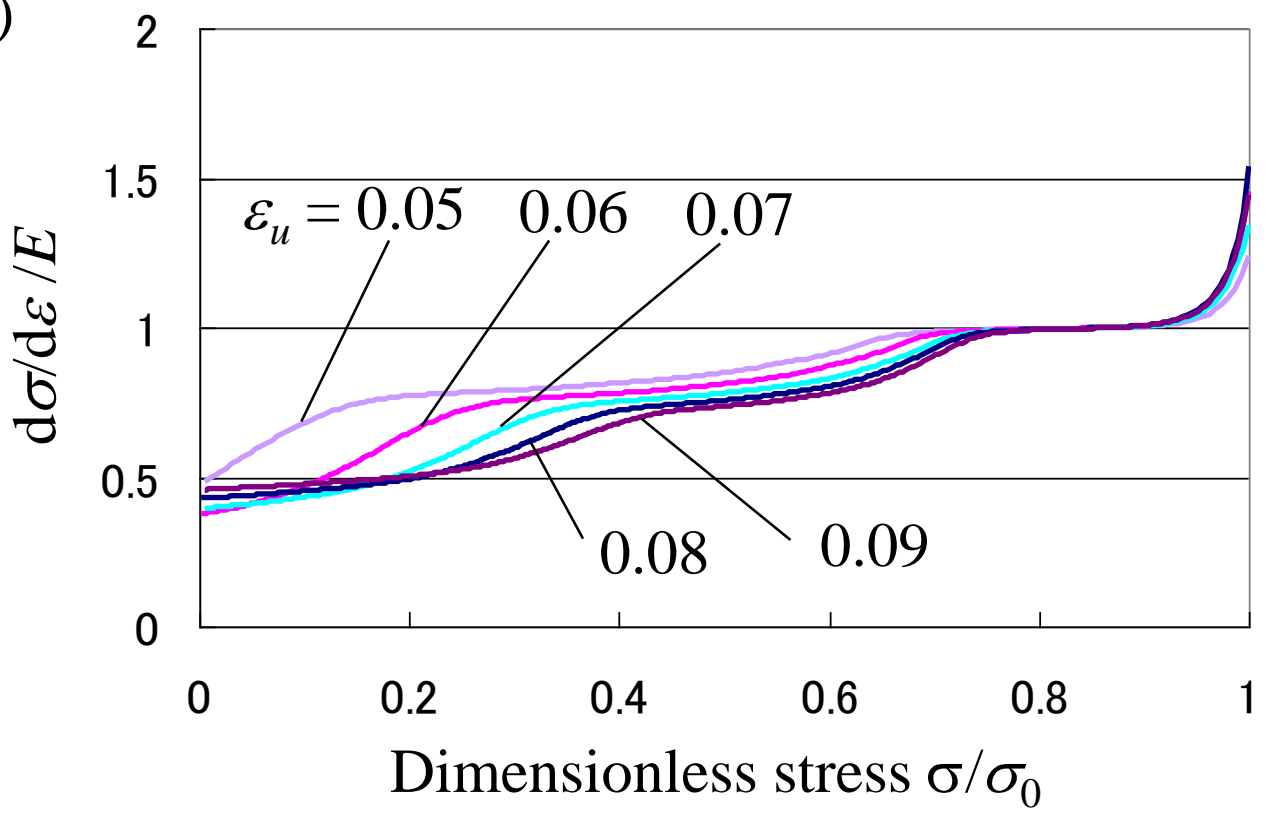

Fig. 8 Variations in instantaneous gradient during unloading obtained by the simulation in the unloaded strain ranges: (a) from 0.001 to 0.04 and (b) from 0.05 to 0.09 . 
(a)

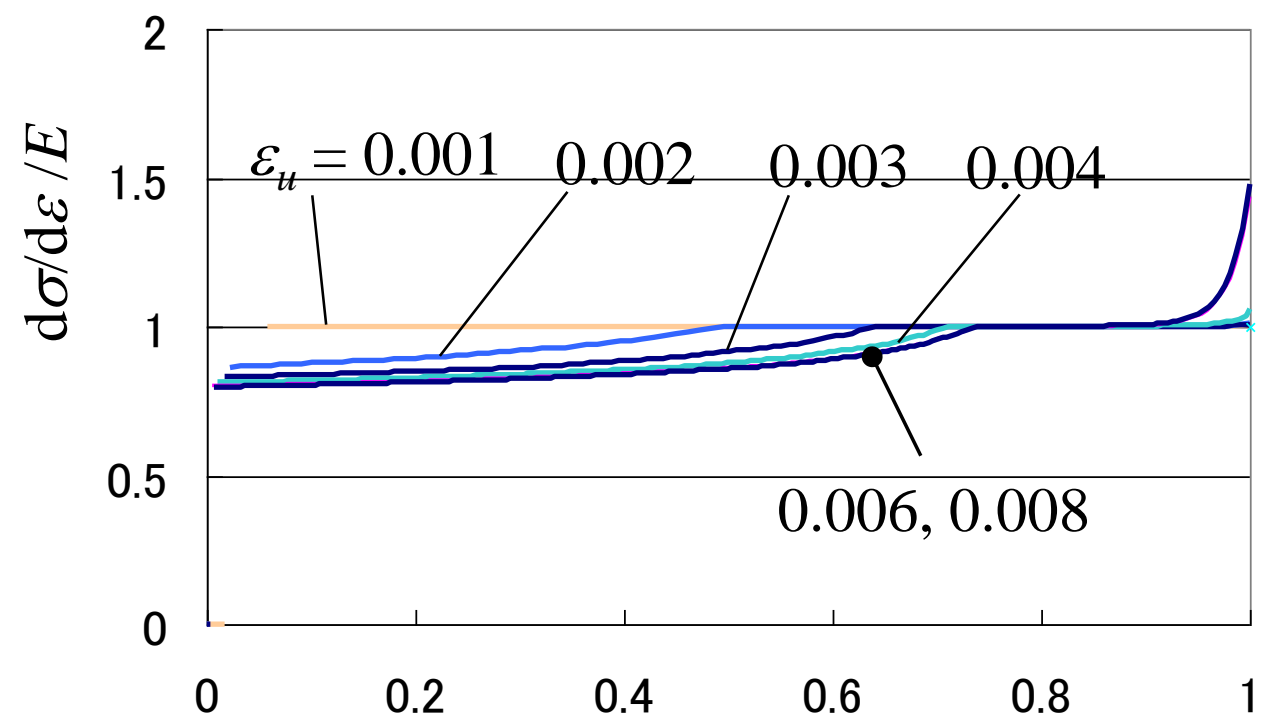

Dimensionless stress $\sigma / \sigma_{0}$

(b)

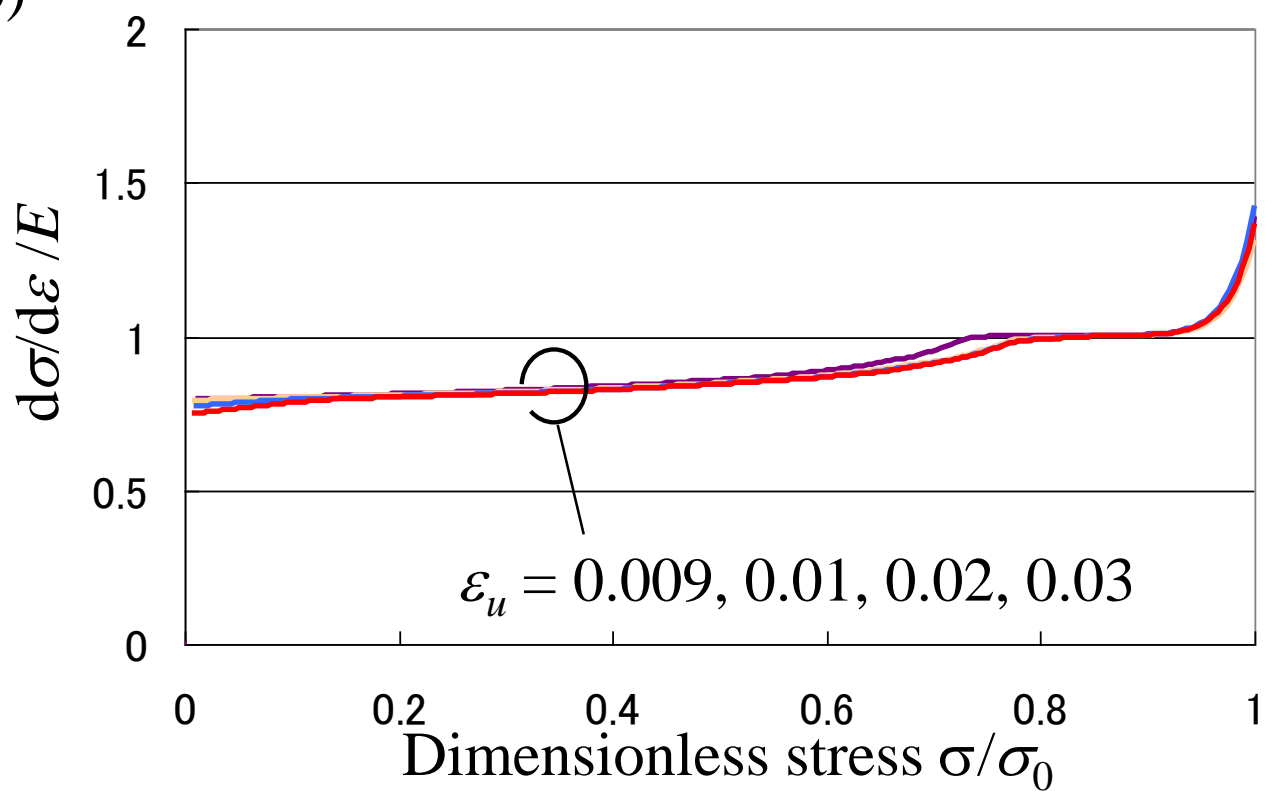

Fig. 9 Variations in instantaneous gradient during unloading under tension obtained by the simulation in the unloaded strain ranges: (a) from 0.001 to 0.008 and (b) from 0.009 to 0.03 . 


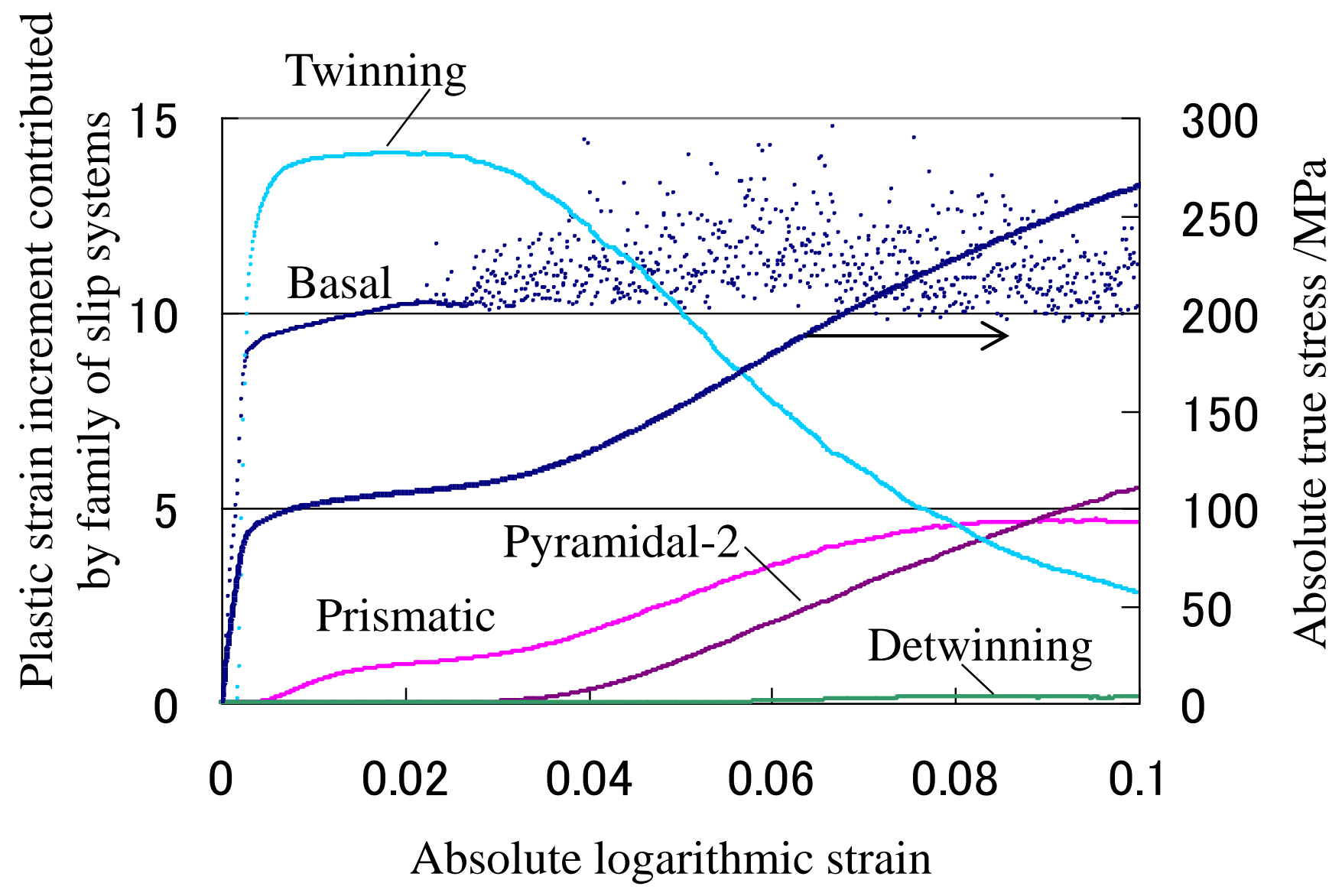

Fig. 10 Plastic strain increment contributed by families of slip and twinning systems during uniaxial compression. 
(a)

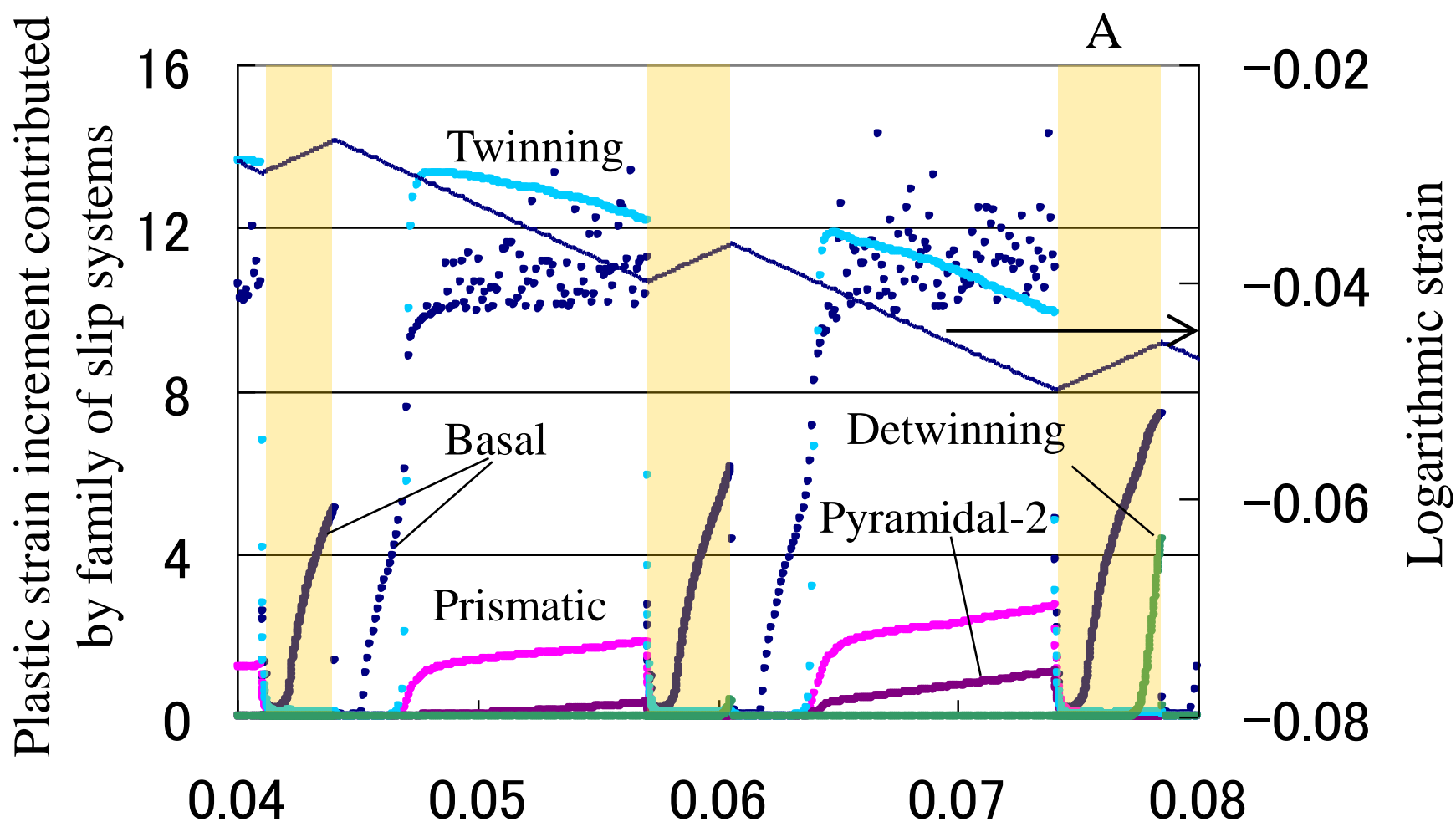

Accumulated absolute strain

Fig. 11 Plastic strain increment contributed by families of slip systems during cyclic loading-unloading in the accumulated absolute strain ranges: (a) from 0.04 to 0.08 and (b) from 0.08 to 0.13 . Shaded areas correspond to unloading processes. 
(b)

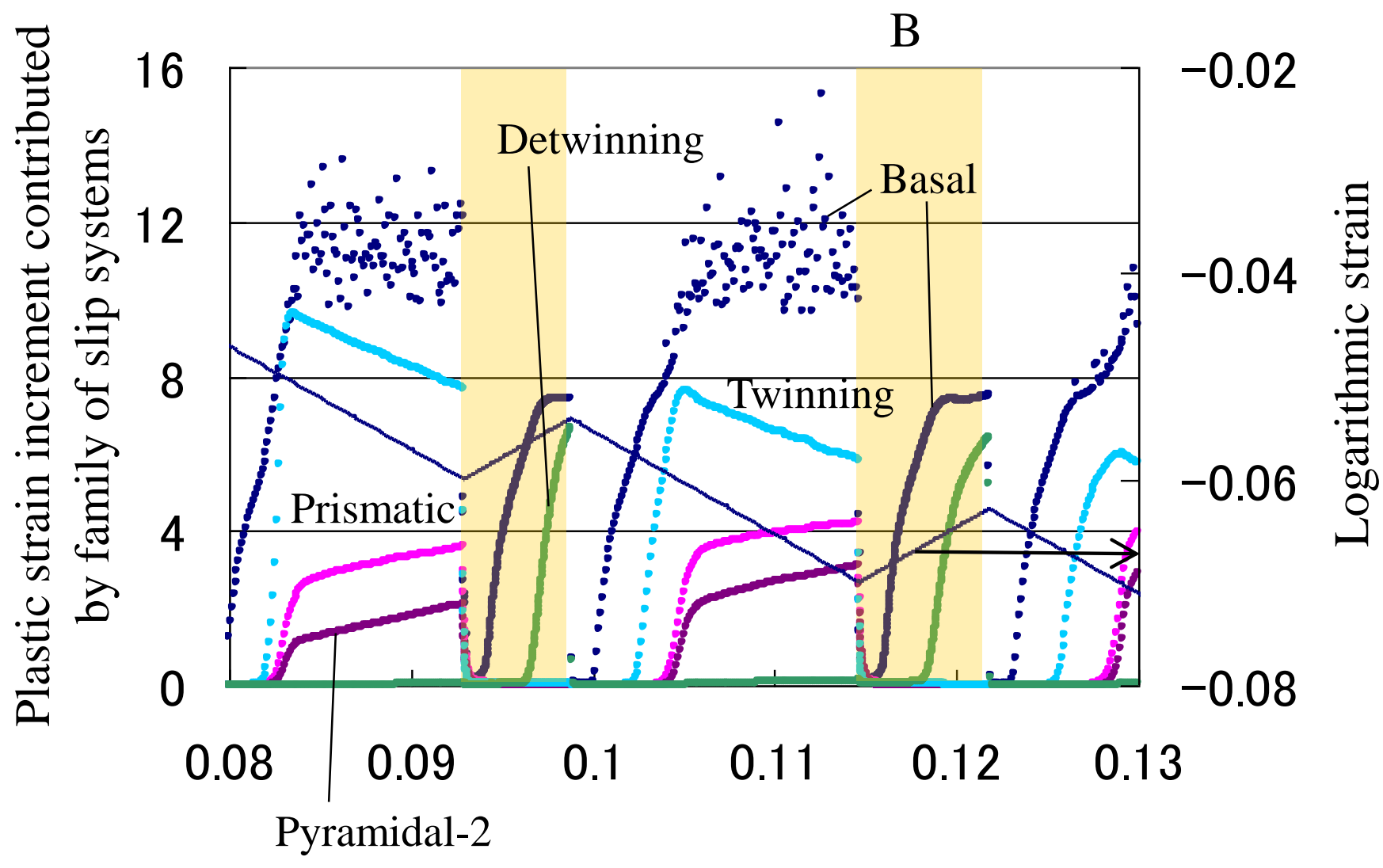

Accumulated absolute strain

Fig. 11 Plastic strain increment contributed by families of slip systems during cyclic loading-unloading in the accumulated absolute strain ranges: (a) from 0.04 to 0.08 and (b) from 0.08 to 0.13 . Shaded areas correspond to unloading processes. 
(a)

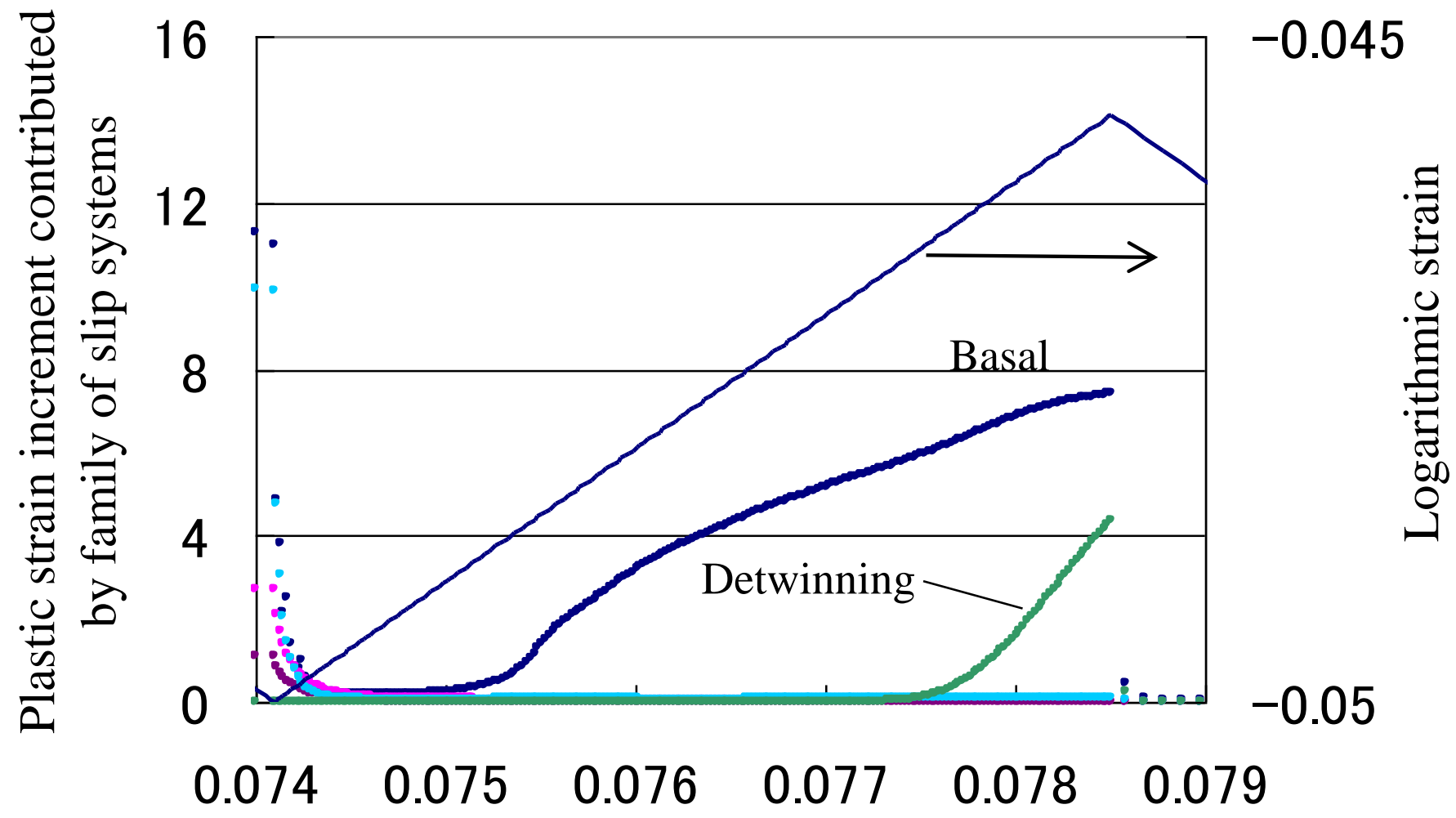

Accumulated absolute strain

Fig. 12 Enlarged figures of designated shaded areas in Fig. 11. Enlarged figure of (a) A (unloaded strain of 0.05) and (b) B (unloaded strain of 0.07) . 
(b)

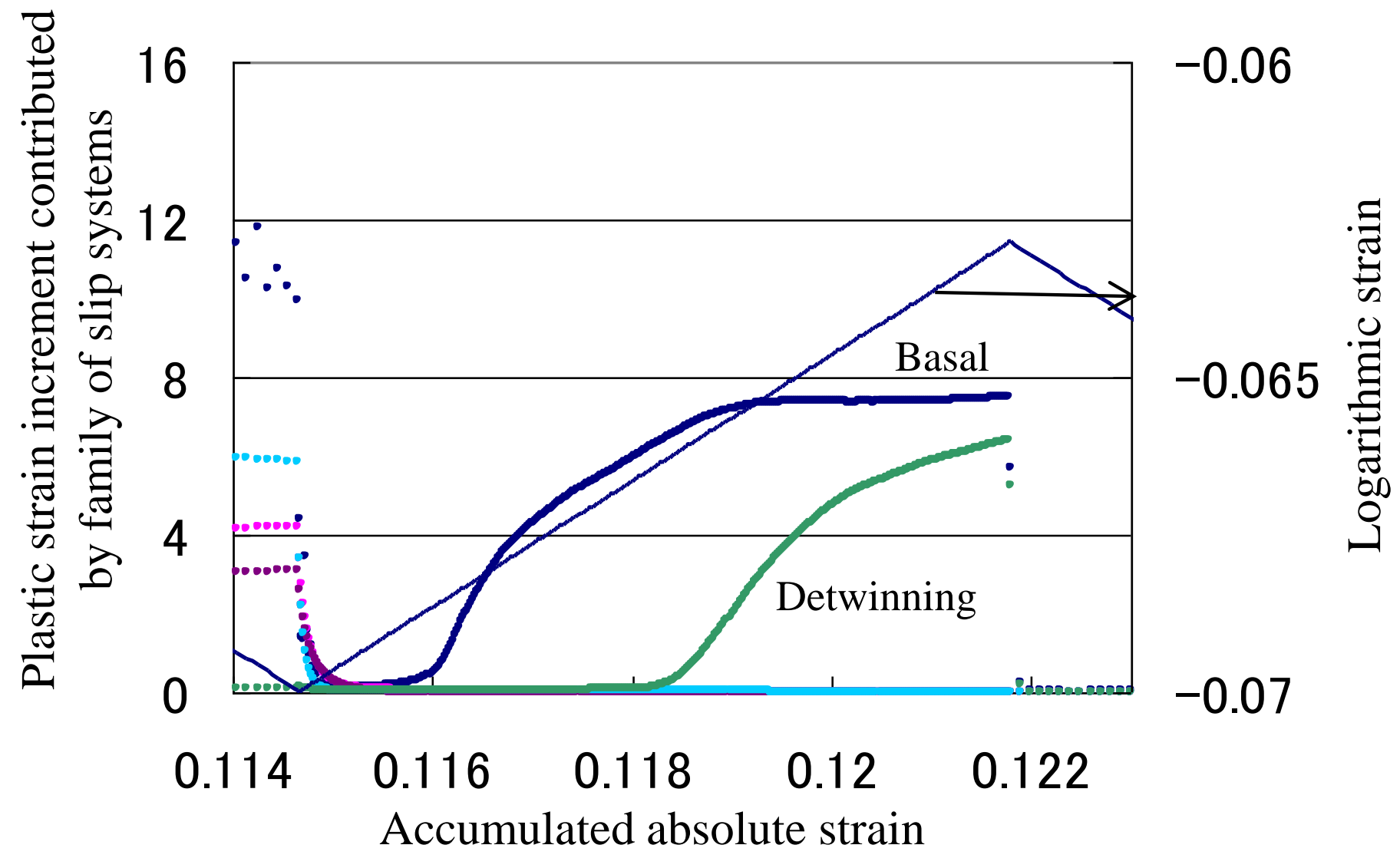

Fig. 12 Enlarged figures of designated shaded areas in Fig. 11. Enlarged figure of (a) A (unloaded strain of 0.05) and (b) B (unloaded strain of 0.07) . 
(a)

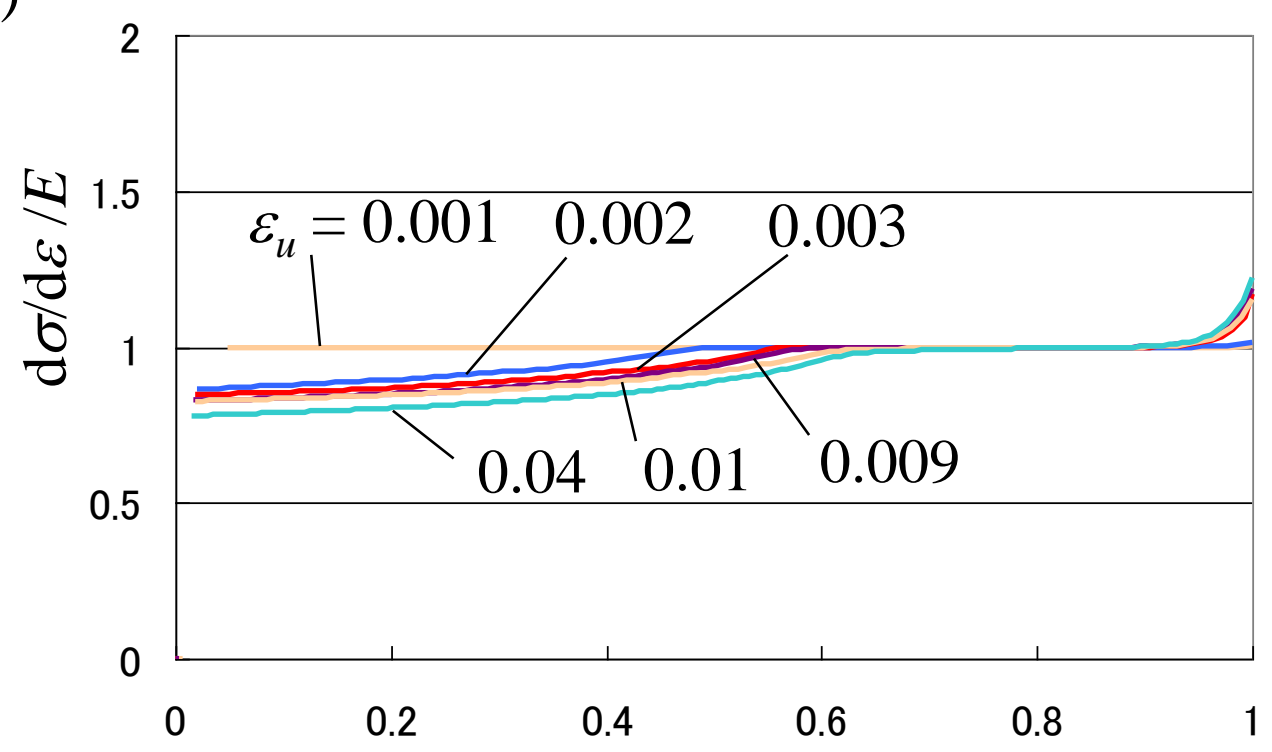

Dimensionless stress $\sigma / \sigma_{0}$

(b)

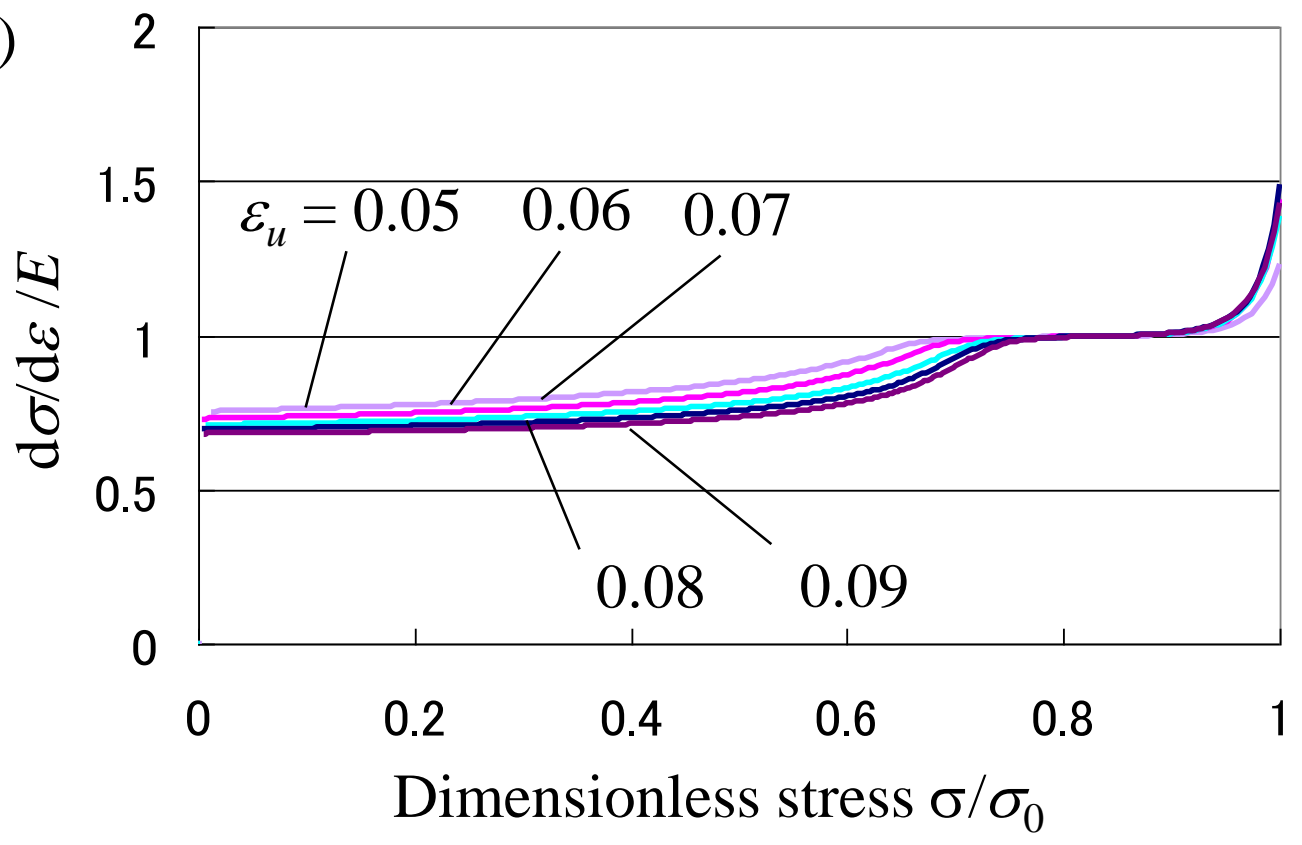

Fig. 13 Variations in instantaneous gradient during unloading obtained by the simulation without considering detwinning in the unloaded strain ranges: (a) from 0.001 to 0.04 and (b) from 0.05 to 0.09 . 
(a)

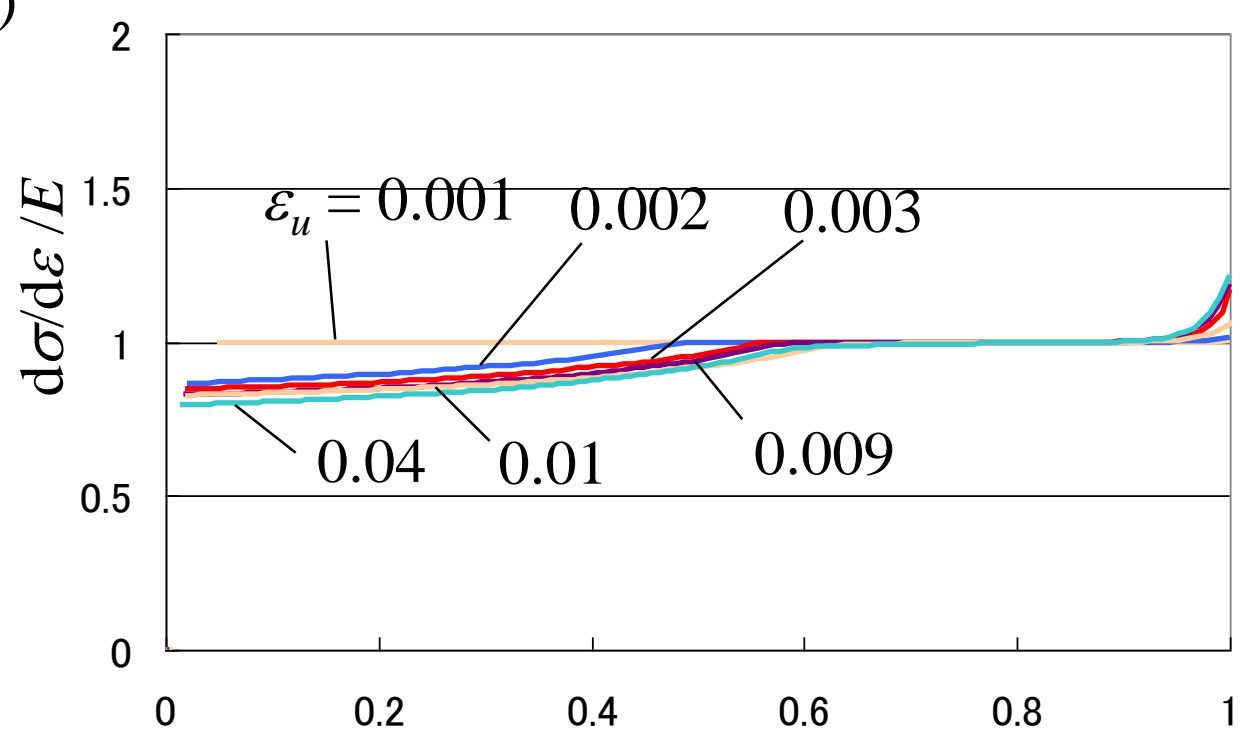

Dimensionless stress $\sigma / \sigma_{0}$

(b)

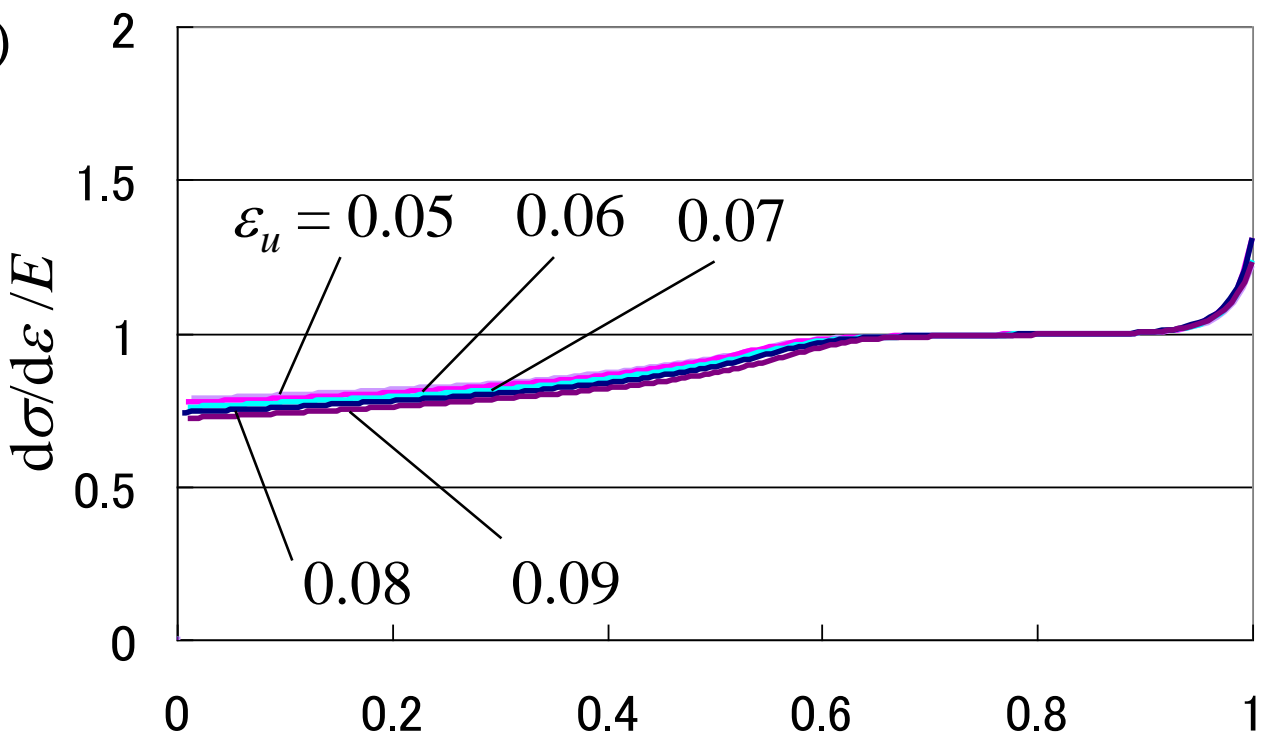

Dimensionless stress $\sigma / \sigma_{0}$

Fig. 14 Variations in instantaneous gradient during unloading obtained by the simulation without considering detwinning and twin reorientation in the unloaded strain ranges: (a) from 0.001 to 0.04 and (b) from 0.05 to 0.09 . 
(a)

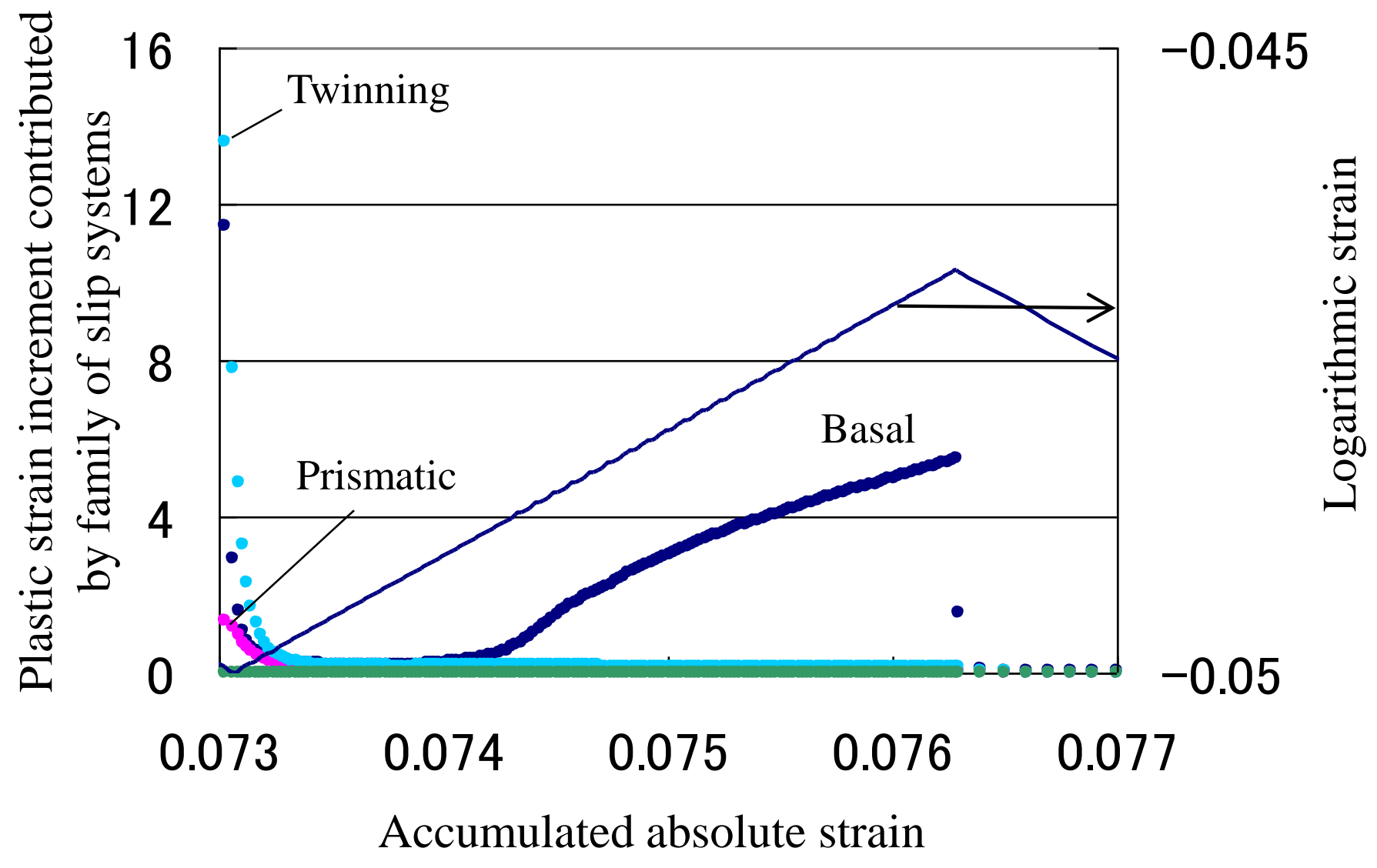

Fig. 15 Evolution of the plastic strain increment during unloading. Unloaded strains of (a) 0.05 and (b) 0.07 . 
(b)

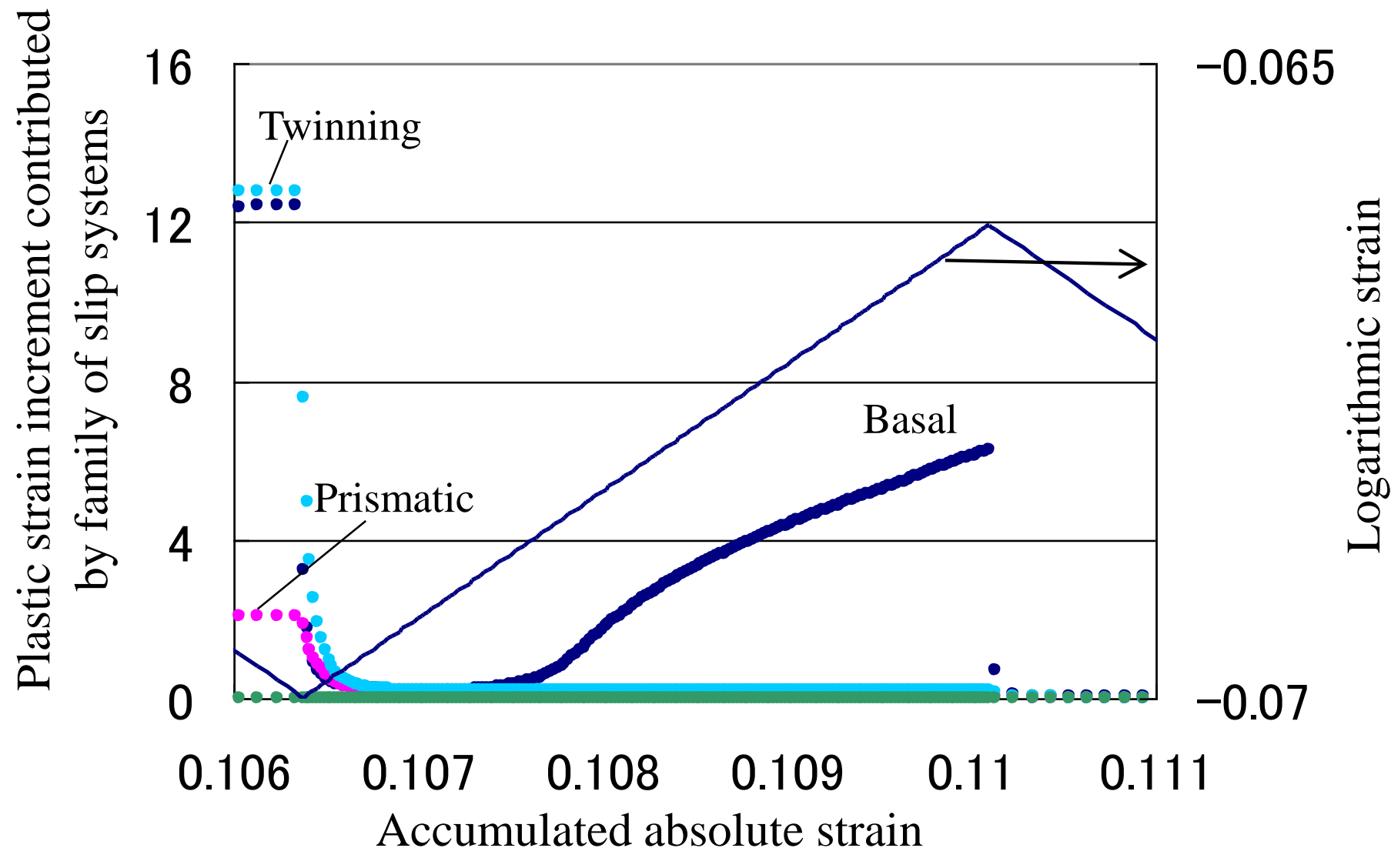

Fig. 15 Evolution of the plastic strain increment during unloading. Unloaded strains of (a) 0.05 and (b) 0.07 . 
Table 1. Plane normal and slip direction vectors of slip and twinning systems used in the present study.

\begin{tabular}{|c|c|c|}
\hline & Slip/twinning plane & $\begin{array}{c}\text { Slip direction/shear direction } \\
\text { due to twinning }\end{array}$ \\
\hline Basal & $\left(\begin{array}{llll}0 & 0 & 0 & 1\end{array}\right)$ & $\left\langle\begin{array}{llll}1 & 1 & \overline{2} & 0\end{array}\right.$ \\
\hline Prismatic & $\left\{\begin{array}{llll}1 & 0 & \overline{1} & 0\end{array}\right\}$ & $\left\langle\begin{array}{llll}1 & 1 & \overline{2} & 0\end{array}\right\rangle$ \\
\hline Pyramidal-2 & $\left\{\begin{array}{llll}1 & 1 & \overline{2} & 2\end{array}\right\}$ & $\left\langle\begin{array}{llll}1 & 1 & \overline{2} & 3\end{array}\right\rangle$ \\
\hline Twinning & $\left\{\begin{array}{llll}1 & 0 & \overline{1} & 2\end{array}\right\}$ & $\left\langle\begin{array}{llll}1 & 0 & \overline{1} & 1\end{array}\right\rangle$ \\
\hline
\end{tabular}


Table 2. Latent-hardening parameters $q_{\alpha \beta}$ used in the present study (Graff et al., 2007) .

\begin{tabular}{ccccc}
\hline & Basal & Prismatic & Pyramidal-2 & Twinning \\
Basal & 0.2 & 0.5 & 0.5 & 0.5 \\
Prismatic & 0.2 & 0.2 & 0.2 & 0.5 \\
Pyramidal-2 & 1.0 & 1.0 & 0.2 & 0.25 \\
Twinning & 1.0 & 1.0 & 0.2 & 0.25 \\
\hline
\end{tabular}


Table 3. Calibrated material parameters in Eqs. (4) and (5).

\begin{tabular}{cccccc}
\hline & Basal & Prismatic & Pyramidal-2 & Twinning Detwinning \\
\hline$\tau_{0} / \mathrm{MPa}$ & 10 & 85 & 160 & 45 & 30 \\
\hline$\tau_{\infty} / \mathrm{MPa}$ & - & 260 & 360 & - & - \\
\hline$h_{0} / \mathrm{MPa}$ & 25 & 700 & 750 & 50 & 50 \\
\hline
\end{tabular}

